Research Article

\title{
Similar Physical Modeling of Roof Stress and Subsidence in Room and Pillar Mining of a Gently Inclined Medium-Thick Phosphate Rock
}

\author{
Xiaoshuang Li, ${ }^{1,2,3,4}$ Zhifang Liu, ${ }^{1}$ and Shun Yang $\mathbb{D}^{1}$ \\ ${ }^{1}$ School of Resources and Environmental Engineering, Jiangxi University of Science and Technology, Ganzhou, \\ Jiangxi 341000, China \\ ${ }^{2}$ School of Resources Engineering, Xi'an University of Architecture and Technology, Xi'an, Shanxi 710000, China \\ ${ }^{3}$ Sinosteel Maanshan General Institute of Mining Research Co. Ltd., Maanshan, Anhui 243000, China \\ ${ }^{4}$ State Key Laboratory of Safety and Health for Metal Mines, Maanshan, Anhui 243000, China \\ Correspondence should be addressed to Shun Yang; shunyang202016@163.com
}

Received 24 December 2020; Revised 24 February 2021; Accepted 3 April 2021; Published 26 April 2021

Academic Editor: Rihong Cao

Copyright (C) 2021 Xiaoshuang Li et al. This is an open access article distributed under the Creative Commons Attribution License, which permits unrestricted use, distribution, and reproduction in any medium, provided the original work is properly cited.

\begin{abstract}
Gently inclined medium-thick orebodies are generally recognized as the most difficult type of orebody to mine, using current available strategies (i.e., the room and pillar method). In the present study, a similar physical model was used to investigate the roof stress and subsidence for mining gently inclined medium-thick phosphate rock from the Jinning Phosphate Mine, Yunnan Province, China. The stress field, displacement field, and roof failure evolution characteristics of the surrounding rock with stope structures of $3 \mathrm{~m}, 5 \mathrm{~m}$, or $8 \mathrm{~m}$ ore pillars were considered. The results showed that, after mining stopped, obvious pressure relief areas formed above the three stope structures, and pressure-bearing areas formed at the front of the roof. With extending the mining in the working face, the stress relief boundary also gradually increased, and the top of the roof tended to sink with a maximum subsidence of $-14.58 \mathrm{~mm},-4.67 \mathrm{~mm}$, and $-3.48 \mathrm{~mm}$. Due to the mining activity, the overlying strata bent and subsided from top to bottom, creating bending subsidence, fracture, and caving zones.
\end{abstract}

\section{Introduction}

Gently inclined medium-thick orebodies are generally defined as those characters with a thickness of 5-15 $\mathrm{m}$ and a dip angle of $5-50^{\circ}$. The effective method of mining them has an intense interest in a wide range of rock engineering processes [1-4]. The thickness and dip angle of an orebody limit the flexible use of trolleybuses, which is a major problem in the mine output due to result in excessive losses. The room and pillar mining method has been considered as an effective mining strategy for gently inclined medium-thick orebodies [5-7]. However, this method greatly disturbs the initial stress within the rock. Due to mining activity, the overlying rock mass of the stope undergoes continuous dynamic changes in its stress and displacement fields under spatiotemporal dimension.
Most previous research in terms of metal and coal mines has only focused on gently inclined medium-thick phosphate orebodies [8-11]. These investigations considered deformation and failure laws of the overlying rock mass affected by the stope parameters, room and pillar mining size, and the roof; for example, previous studies indicated that the careful selection of stope parameters plays an important role in ensuring a safe mining environment and in protecting surrounding buildings [12-16]. The load-bearing capacity of an ore pillar is positively related to its size $[17,18]$. Zhao et al. [19] considered the influence of burial depth and used Platts' theory to derive a theoretical formula for the optimal ore pillar size, combining this with the characteristics of phosphate rock. Li and Chai [20] established a mechanical model based on the medium-thick plate theory for metal mine caving and filling isolation pillars for 
selection of the pillar size. Wang et al. [21] used a numerical and similar physical model to analyze the stress and deformation of the roof and the failure rules for the overlying rock. Guan et al. [22] investigated a gently inclined mediumthick gold orebody by the numerical and physical models to assess the displacement and surface settlement rules for the overlying rock in a filling stope. Steel fiber-reinforced shotcrete is adopted by Zhang et al. [23] to improve the excavation rate and guarantee the safety of roadways when passing through unfavorable geological bodies.

However, phosphorite rock mines differ from metal and coal mines in terms of the orebody morphology, metallogenic regularity, stratum structure, and tectonic stress. The lower the rock strength, the higher the swelling, and rheological characteristics make the roof structure around an ore pillar more likely to fail under the mining and water load. Thus, the objective of this study is to explore the deformation and failure laws for the rock surrounding the roof of a gently sloping medium-thick phosphate rock in room and pillar mining and to consequently identify an optimal stope structure within the No. 6 mining area of the Jinning Phosphate Mine in Yunnan Province, China. Similar physical experiments were adopted to investigate the rock mass stability of three stope structures consisting of $3 \mathrm{~m}, 5 \mathrm{~m}$, and $8 \mathrm{~m}$ ore pillars. The findings of this study are of particular use for geotechnical engineering on providing guidelines for mining similar phosphate rocks to ensure the sustainable development of mining systems.

\section{Engineering Background}

The Jinning Phosphate Mine is located in Kunming City, Yunnan Province, China (see Figure 1). Figure 1 shows the location of the mine (see Figure 1(a)), the remote sensing image of the mine (see Figure 1(b)), and the current mine structure (see Figure 1(c)). It is a large sedimentary rock phosphate deposit located in the hinterland of the Yunnan Plateau. The elevation ranges from $2202.0 \mathrm{~m}$ to $2459.3 \mathrm{~m}$ above sea level. The single ore bed has a monoclinal structure that runs from north to south. The average thickness of the industrial layer is $10.45 \mathrm{~m}$, with a phosphate ore percent of $26-30 \%$. The orebody is classified as a gently inclined medium-thick phosphate orebody. After decades of pit mining, the western area of the No. 6 pit has been fully mined. The eastern area has a mining depth of $150-180 \mathrm{~m}$, a $1000 \mathrm{~m}$ trend extension, and an inclination angle of $40-50^{\circ}$. If the phosphate rock had continued to be mined using an open pit, the mining operation would lose the economic and technical advantages. The transition from open pit to underground orebody mining would be the best strategy.

For underground mining, the roof rock and the mining pillars of a stope form a unified system, and the stability of the stope is determined by its structural parameters. Before the orebody is excavated, the stress in each stope is balance. After the initial orebody is excavated, the stress in the surrounding rock is redistributed.

This study was designed to investigate the stress and displacement laws of a gently inclined medium-thick phosphate rock and the rock surrounding a stope in room and pillar mining after continuous excavations. It is well known that the experiment/test is the most reliable way to study mechanical problems [24-37]; therefore, in this paper, a similar physical model was adopted with a stope structure consisting of a size of $10 \times 10 \mathrm{~m}$ room with $3 \times 3 \mathrm{~m}, 5 \times 5 \mathrm{~m}$, and $8 \times 8 \mathrm{~m}$ pillars, respectively. The stress distribution of the surrounding rock, the change in the subsidence displacement of the overlying rock mass, and the roof deformation and failure laws were explored. Based on the deformation and failure of the surrounding rock, optimal structural parameters for the stope were identified.

\section{Experimental Model Design}

Experimental study needs a good design plan [38-51], and the No. 6 mining area of the Jinning Phosphate Mine is divided into nine rock strata based on a geological investigation. The depth of the rock strata ranges from $+2283 \mathrm{~m}$ to $+2050 \mathrm{~m}$. The main phosphate rock strata have a burial depth of $+2150 \mathrm{~m}$ and a thickness of $13.30 \mathrm{~m}$.

The model frame size is determined according to the prototype size and geometric similarity ratio. A plane stress model was selected for the simulation experiment with a model frame size of $3.00 \times 0.30 \times 2.00 \mathrm{~m}$ (length $\times$ width $\times$ height). In order to obtain similar experimental parameters, a preliminary uniaxial mechanical experiment was conducted, and the model similarity was determined based on similarity theory $[52,53]$. The geometrical similarity ratio, time similarity ratio, strength similarity ratio, and bulk density similarity ratio are $1: 240,1: 16,1$ : 296.3 , and $1: 1.23$, respectively. The initial conditions and boundary conditions of the model can be approximated as a homogeneous gravity field based on the field stress field data, which is similar to the prototype.

In the similar physical model, river sand, gypsum, and calcium carbonate were employed as the main aggregates. Cement, sawdust powder, mica, plastic, and motor oil were used as auxiliary materials. Borax and mica powder were used for the retarder and the sandwich material. Using an orthogonal experiment, 40 experimental proportioning schemes were designed and screened. Material proportioning schemes with similar mechanical properties to the prototype were selected. According to the geological conditions of the mining area, 9 types of rock formations were set up in this test and distinguished by different colors. The details are illustrated in Tables 1 and 2 .

\section{Experimental Excavation Plan}

The similar physical model was used to investigate three stope structures, with a size of $4.1 \times 4.1 \mathrm{~cm}$ mine room with $1.2 \times 1.2 \mathrm{~cm}, 2 \times 2 \mathrm{~cm}$, and $3.3 \times 3.3 \mathrm{~cm}$ pillars. Based on the geometrical similarity ratio (i.e., $1: 240$ ), the actual size of pillars was $10 \times 10 \mathrm{~m}$ room with $3 \times 3 \mathrm{~m}, 5 \times 5 \mathrm{~m}$, and $8 \times 8 \mathrm{~m}$ pillars. Each stope structure was divided into nine mine rooms by using four excavation steps. An electric drill was adopted to excavate mine room once every 2 hours (total twice). The first step included mine room \#1, the second step included mine rooms \#2 and \#3, 

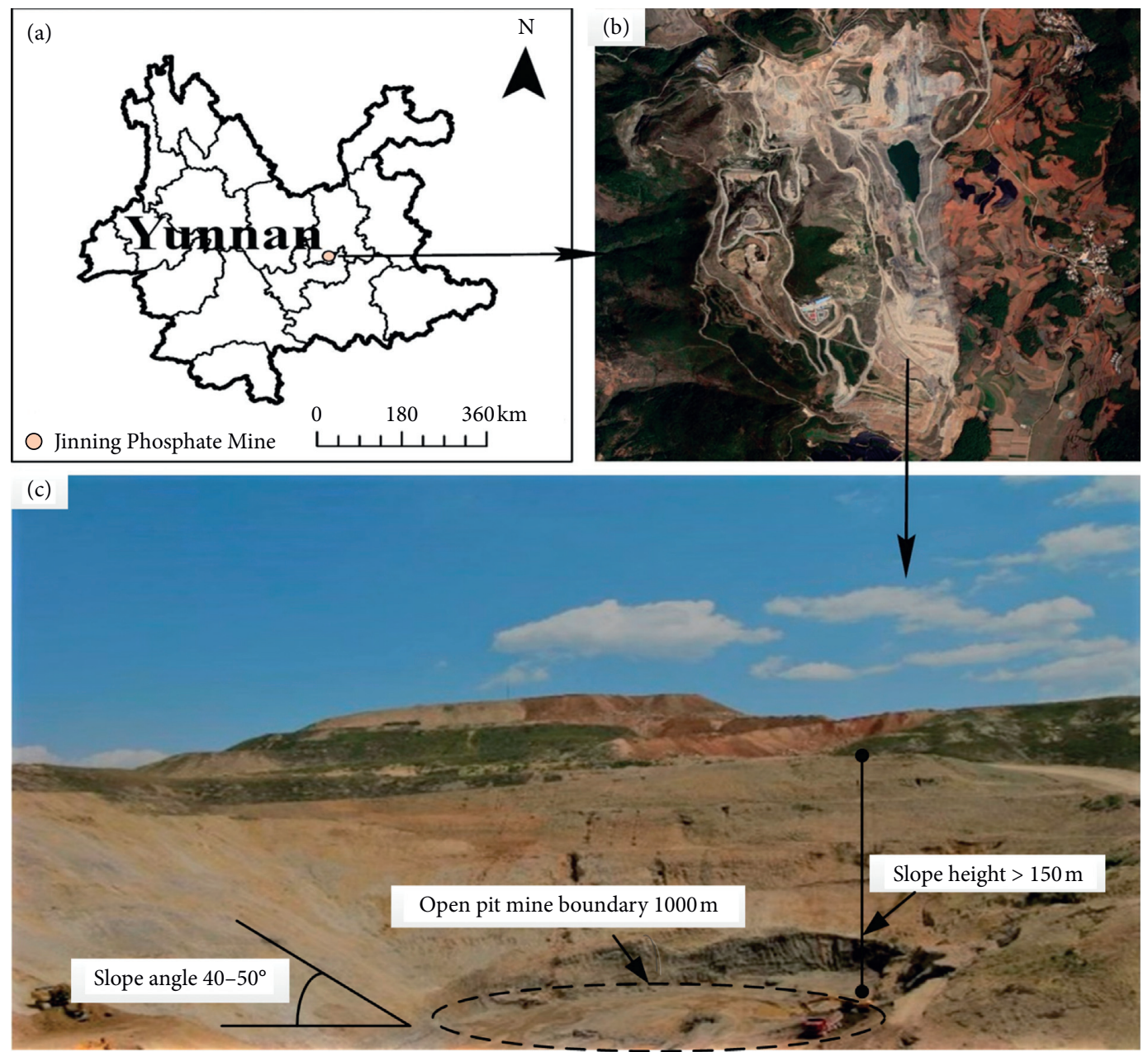

FIgURE 1: Geographical position and current mining operations at the Jinning Phosphate Mine in 2015: (a) location of the mine; (b) remote sensing image of the mine; (c) the current mine structure.

TABle 1: Proportion of the materials in each rock stratum of the similar physical model.

\begin{tabular}{cccc}
\hline Rock stratum & $\begin{array}{c}\text { Material ratio (sand: calcium } \\
\text { carbonate: gypsum) }\end{array}$ & $\begin{array}{c}\text { Actual rock } \\
\text { thickness (m) }\end{array}$ & $\begin{array}{c}\text { Similar physical model } \\
\text { thickness (cm) }\end{array}$ \\
\hline Sandy soil & $6: 7: 3$ & 17.04 & 7.10 \\
Medium- to coarse-grained dolomite & $4: 2: 8$ & 104.00 & 43.33 \\
Bedded argillaceous dolomite & $4: 5: 5$ & 9.00 & 3.75 \\
Quartz sandstone & $3.8: 5: 5$ & 17.80 & 7.42 \\
Phosphate ore & $3: 2: 8$ & 13.30 & 7.87 \\
Low-grade phosphorus ore & $3.2: 3: 7$ & 3.06 & 2.11 \\
Boundary ore & $3.8: 4: 6$ & 16.00 & 6.67 \\
Light grey primary dolomite & $3.5: 3: 7$ & 33.50 & 13.96 \\
\hline
\end{tabular}

the third step included mine rooms \#4-6, and the fourth step included mine rooms \#7-9. The details are illustrated in Figure 2.

Stress sensors were used to monitor changes in the stress within the phosphate rock roof. Changes in displacement were monitored by using electronic total stations, and a camera was used to record the deformations of the surrounding rock and pillars.

\section{Arrangement of Stress and Displacement Observation Points}

A WS3811-J12 static resistance strain collector and BX-1 series soil sensors were installed to monitor roof stress. Stress observation points were located at a longitudinal distance of $6.3 \mathrm{~cm}$ and $10.4 \mathrm{~cm}$ from the phosphate rock stratum, with a horizontal distance of $25 \mathrm{~cm}, 108.3 \mathrm{~cm}$, 
TABLE 2: Materials used in the rock strata of the similar physical model.

\begin{tabular}{|c|c|c|c|c|c|}
\hline Rock stratum & Sand $(\mathrm{kg})$ & Calcium carbonate $(\mathrm{kg})$ & Gypsum (kg) & Water $(\mathrm{kg})$ & Borax $(\mathrm{kg})$ \\
\hline Sandy soil & 88.73 & 10.35 & 4.44 & 11.50 & 115.00 \\
\hline Medium- to coarse-grained dolomite & 505.40 & 25.27 & 101.09 & 70.19 & 701.90 \\
\hline Bedded argillaceous dolomite & 43.74 & 5.47 & 5.47 & 6.07 & 60.70 \\
\hline Gravel quartzite & 85.64 & 11.27 & 11.27 & 12.02 & 120.20 \\
\hline Phosphate ore & 60.58 & 4.04 & 16.16 & 8.97 & 89.70 \\
\hline Low-grade phosphorus ore & 78.10 & 7.32 & 17.08 & 11.39 & 113.90 \\
\hline Boundary ore & 24.35 & 2.56 & 3.85 & 3.42 & 34.20 \\
\hline Light grey primary dolomite & 75.64 & 6.48 & 15.13 & 10.81 & 108.10 \\
\hline Deep grey medium-thick layered primary dolomite & 158.31 & 15.83 & 29.40 & 22.62 & 226.20 \\
\hline
\end{tabular}

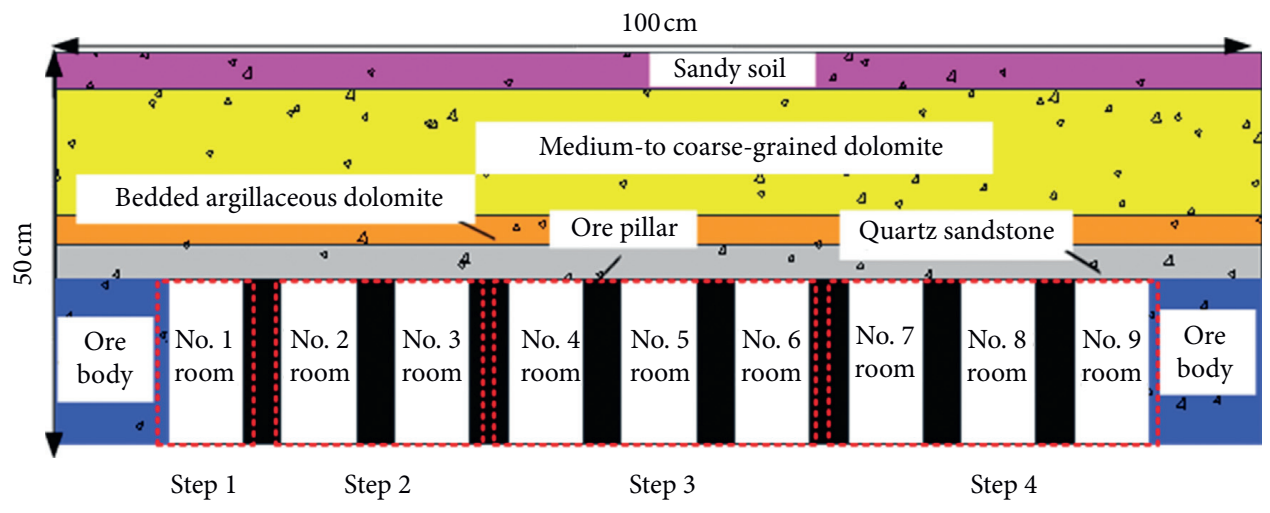

FIGURE 2: Mine room excavation plan.

and $201.6 \mathrm{~cm}$ from the model endpoint for pillar sizes of $1.2 \mathrm{~cm}, 3.3 \mathrm{~cm}$, and $2 \mathrm{~cm}$, respectively. The intervals for the stress points were $8.3 \mathrm{~cm}, 10.4 \mathrm{~cm}$, and $12.5 \mathrm{~cm}$ for the three pillar sizes, respectively. The details are illustrated in Figure 3.

A Nikon DTM-502 total station was used to monitor rock layer displacement. The first horizontal displacement line was located $19.1 \mathrm{~cm}$ away from the endpoint of the model. The horizontal interval of the displacement points was $11.6 \mathrm{~cm}$, and seven observation points were positioned on each measurement line at longitudinal distances of $6.25 \mathrm{~cm}, 10.4 \mathrm{~cm}, 14.5 \mathrm{~cm}, 22.9 \mathrm{~cm}, 31.2 \mathrm{~cm}, 43.7 \mathrm{~cm}$, and $56.2 \mathrm{~cm}$ from the phosphate rock stratum (marked as 1-7 in the model). A total of 22 displacement observation lines and 154 displacement observation points were used in the model, as shown in Figure 4.

\section{Test Results and Analysis}

By monitoring the stress points, it was found that the initial stress of the three stope structures was the same, with the stress before excavation positively correlated with the buried depth. In particular, the stress at M1, M2, $\mathrm{N} 1, \mathrm{~N} 2, \mathrm{P} 1$, and $\mathrm{P} 2$ was $12.00 \mathrm{kPa}$, while the stress at M3-M6, N3-N6, and P3-P6 was $12.40 \mathrm{kPa}$. Maps of the initial stress distribution were rendered using MATLAB software with cubic spline interpolation (see Figure 5). Because of the same initial stress of the stope structures, only the structure with $1.2 \mathrm{~cm}$ pillars is presented.
6.1. Stope Deformation and Failure Laws for Mine Rooms with $3 \mathrm{~m}$ Ore Pillars. Data from the stress measurement points and the displacement measurement lines for all three stope structures were processed in MATLAB with cubic spline interpolation. The stress nephogram and subsidence displacement nephogram of the surrounding rock for the stope structure with $1.2 \mathrm{~cm}$ pillars based on the M1-M6 stress measurement points and the L1-L5 displacement measurement lines are presented in Figures 6 and 7. Figure 6 shows the lower roof stress and overlying rock subsidence for the four-step excavation of the stope structure with $3 \mathrm{~m}$ ore pillars. Figure $6(\mathrm{a})$ and $6(\mathrm{~b})$ represent the first step of excavation; Figures 6(c) and 6(d) represent the second step of excavation step; Figures 6(e) and $6(\mathrm{f})$ represent the third step of excavation; and Figures 6(g) and 6(h) represent the fourth step of excavation. Figure 7 shows the deformation and failure characteristics of the roof for the $3 \mathrm{~m}$ ore pillars. Figure $7(\mathrm{a})$ represents the deformation and failure characteristics of the roof of the first step of excavation; Figure 7(b) represents the deformation and failure characteristics of the roof of the second step of excavation; Figure 7(c) represents the deformation and failure characteristics of the roof of the fourth step of excavation. The displacement measurement points were labeled LB-1, LB-2, LB-3, LB-4, LB-5, LB-6, and LB-7 according to their vertical distance from the stope roof $(6.25 \mathrm{~cm}, 10.4 \mathrm{~cm}, 14.5 \mathrm{~cm}, 22.9 \mathrm{~cm}, 31.2 \mathrm{~cm}$, $43.7 \mathrm{~cm}$, and $56.2 \mathrm{~cm}$, respectively) (B represents the line number). 


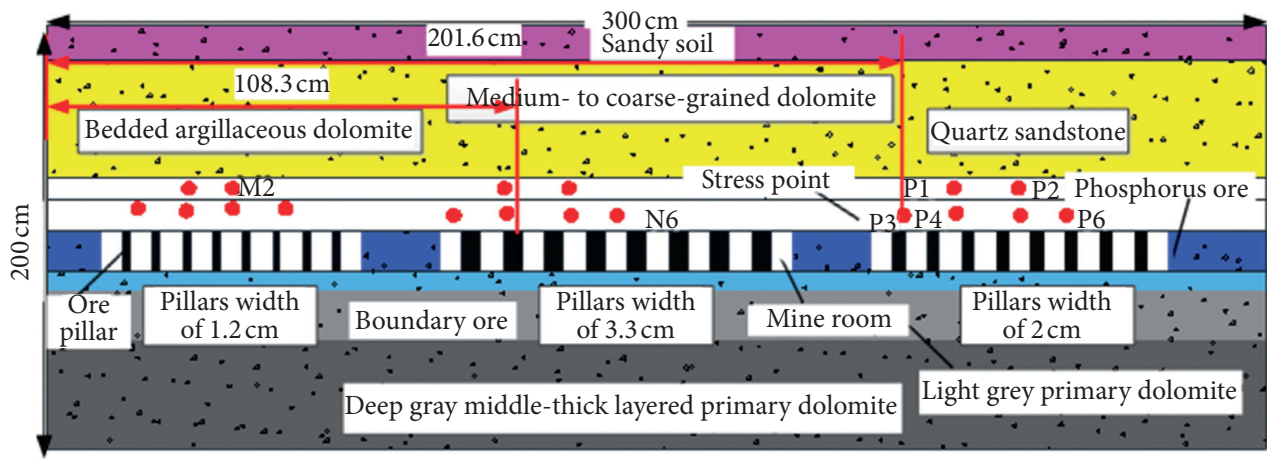

FiguRE 3: Stress point monitoring in the similar physical model. The mining site at the stress measurement points is a size of $10 \times 10 \mathrm{~m}$ room with the width of $3 \times 3 \mathrm{~m}, 5 \times 5 \mathrm{~m}$, and $8 \times 8 \mathrm{~m}$ pillars. These points are labeled M1-M6, N1-N6, and P1-P6, respectively.

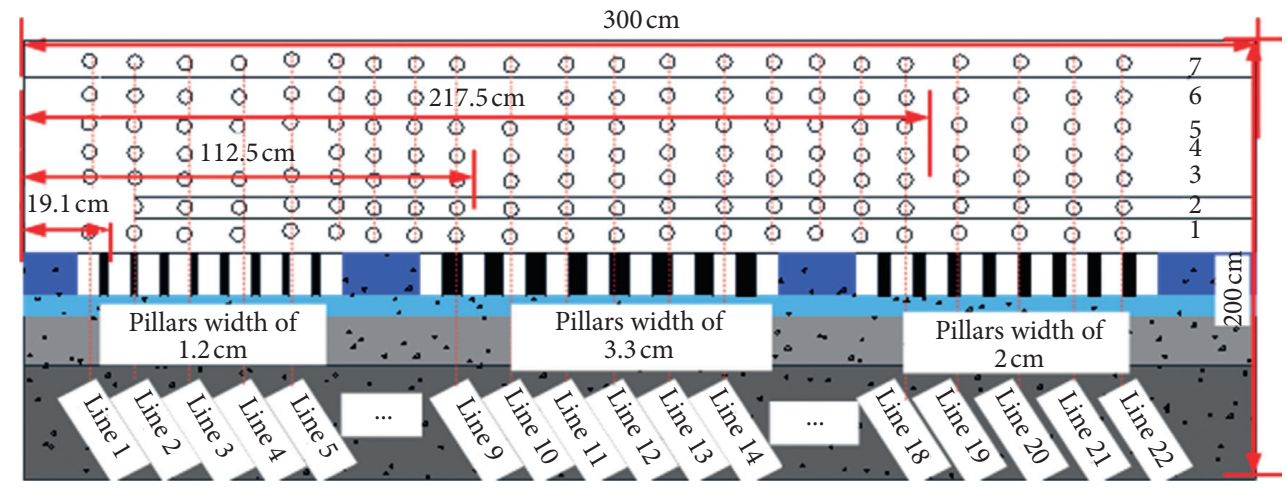

Figure 4: Displacement point monitoring. The measurement lines are marked as Line 1 to Line 22 in order from left to right. Each measurement line has seven measurement points. The measurement points are marked as LB-1, LB-2, LB-3, LB-4, LB-5, LB-6, and LB-7, with $B$ denoting the line number, according to the distance from the stope roof $(6.25 \mathrm{~cm}, 10.4 \mathrm{~cm}, 14.5 \mathrm{~cm}, 22.9 \mathrm{~cm}, 31.2 \mathrm{~cm}, 43.7 \mathrm{~cm}$, and $56.2 \mathrm{~cm}$, respectively).

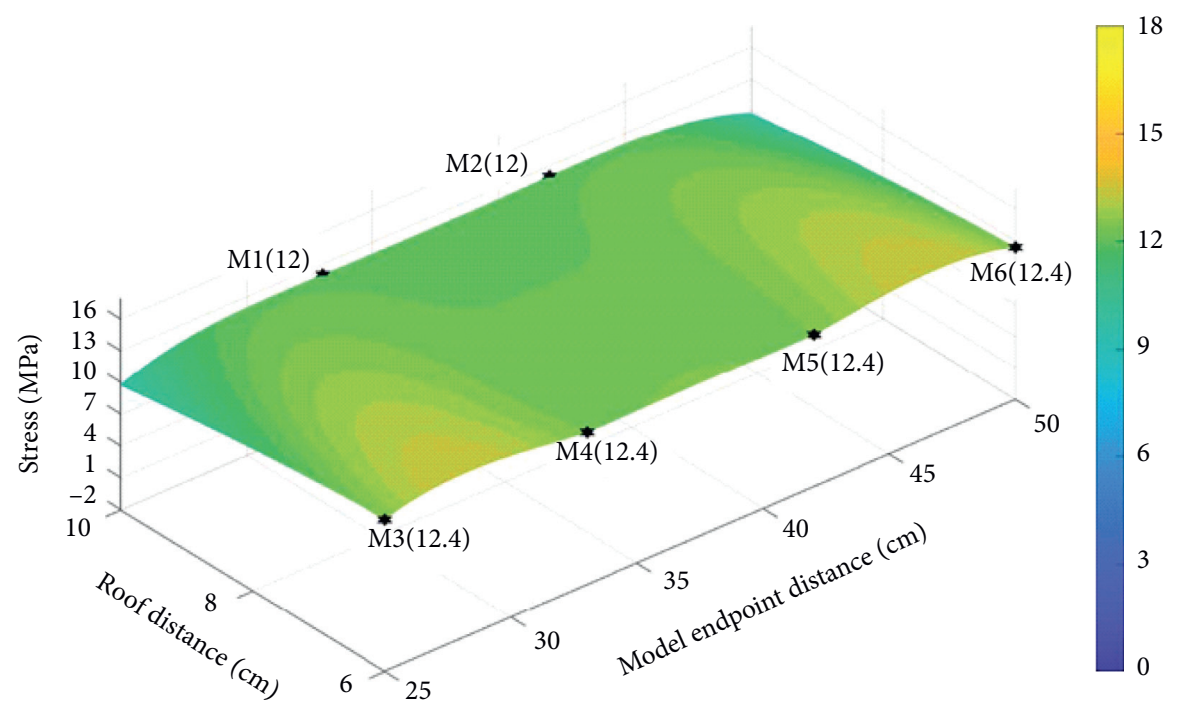

Figure 5: Initial stress distribution

After the first excavation step, mine room \#1 formed a goaf. A pressure relief zone appeared above the roof of the stope, and the M3 stress fell from $12.40 \mathrm{kPa}$ to $11.02 \mathrm{kPa}$. The stress of the overlying rock moved towards the front of the goaf under the influence of mining. The displacement measurement points L1-1 and L1-2 subsided slightly by
$-0.5 \mathrm{~mm}$ (actual scale $-12 \mathrm{~cm}$ ) and $-0.13 \mathrm{~mm}$ (actual scale $-3 \mathrm{~cm}$ ), respectively. There was a slightly loose area above the top plate, but the model was generally stable.

In the second excavation step, the range of the goaf was expanded into mine room \#3. The stress relief area in the roof increased further, achieving the maximum stress relief 


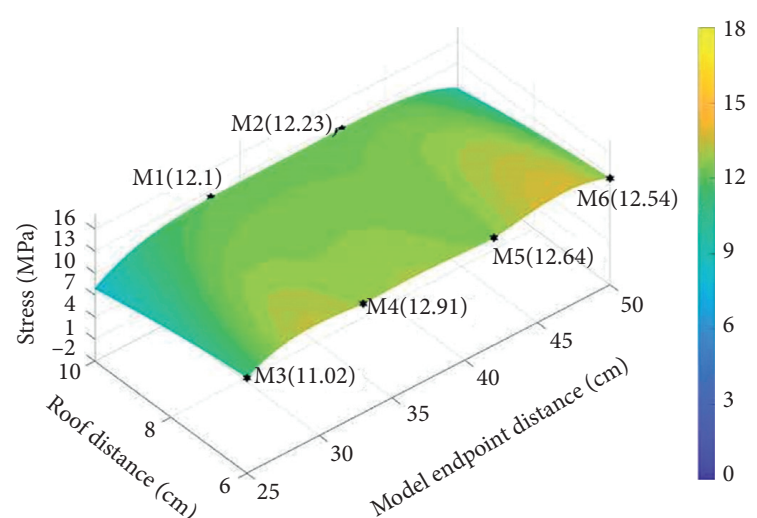

(a)

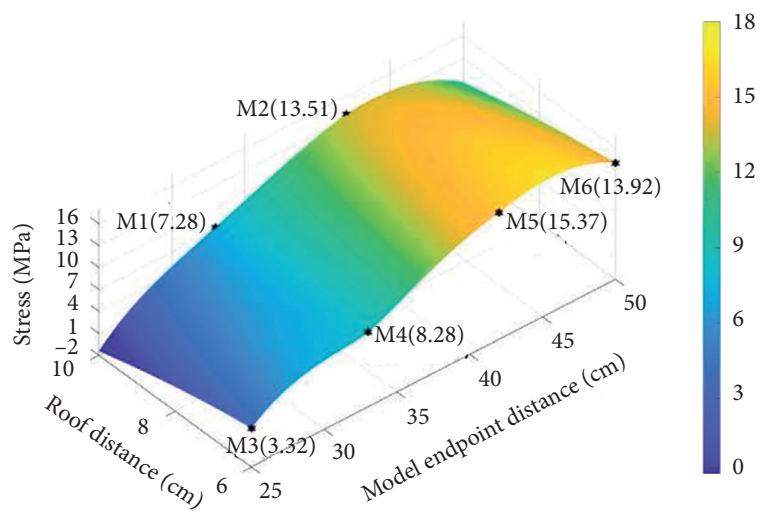

(c)

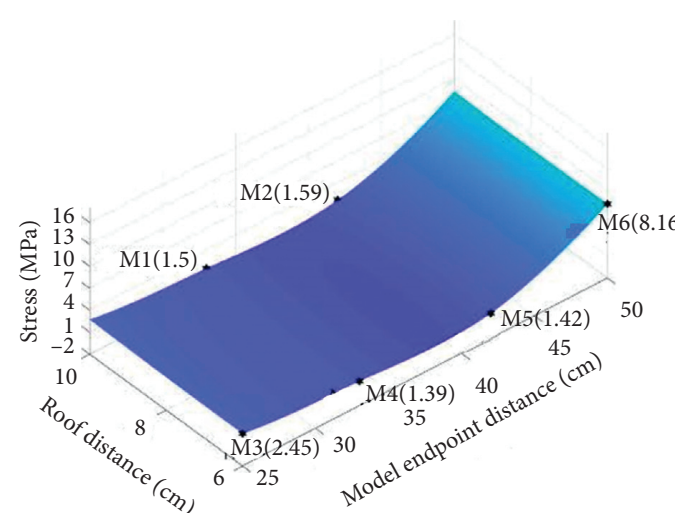

(e)

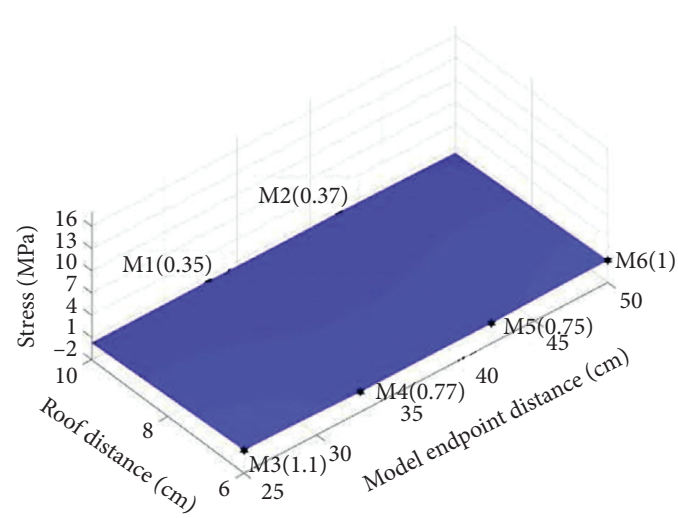

(g)

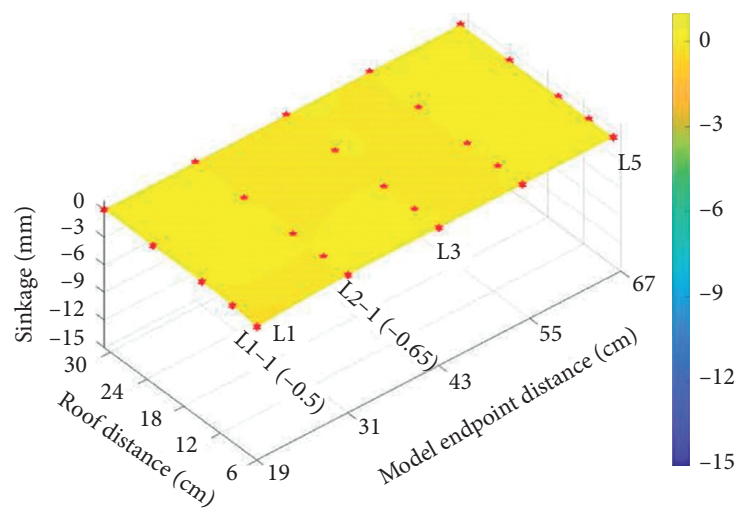

(b)

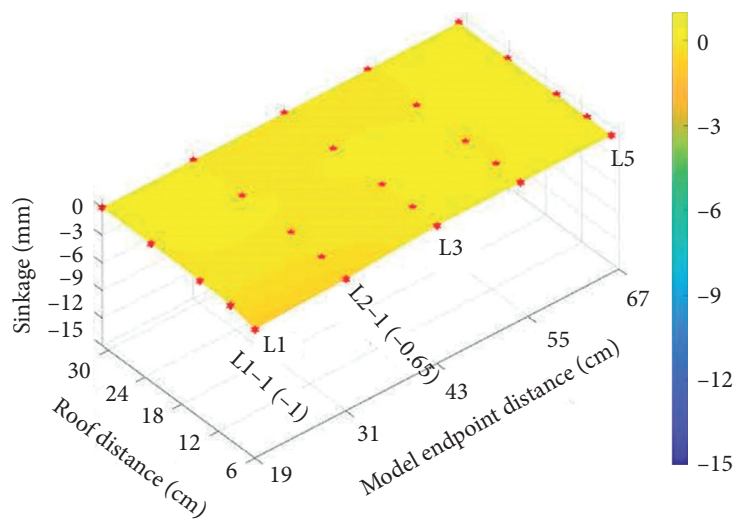

(d)

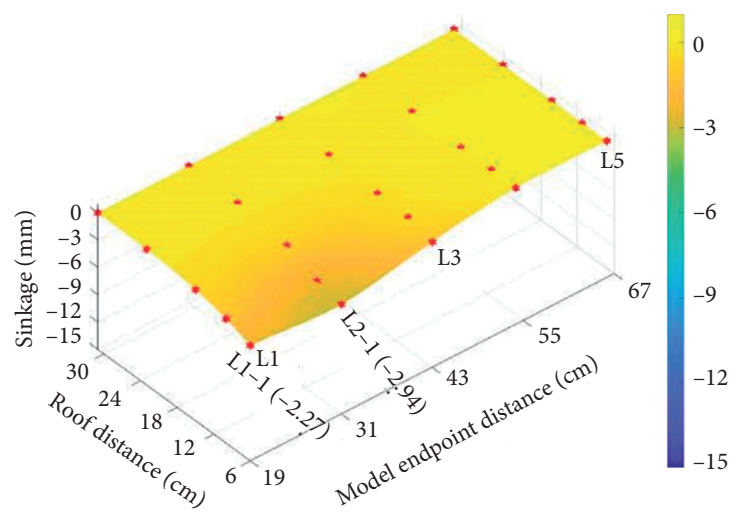

(f)

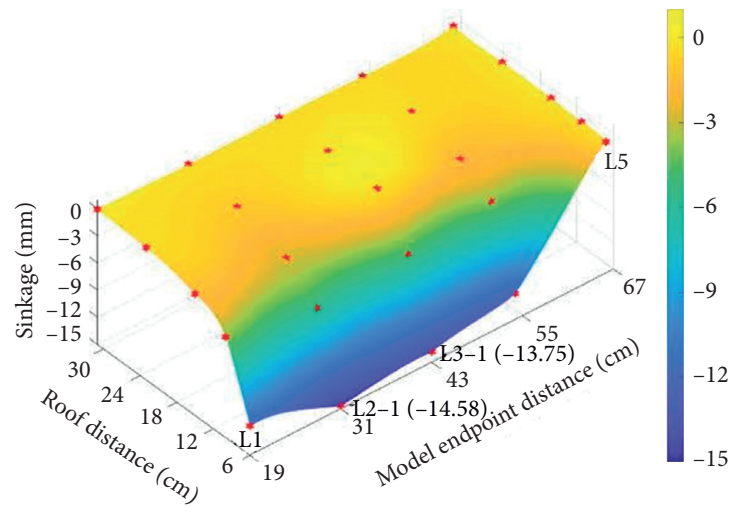

(h)

FIGURE 6: Lower roof stress and overlying rock subsidence for the four-step excavation of the stope structure with $3 \mathrm{~m}$ ore pillars: (a, b) first step; (c, d) second step; (e, f) third step; and (g, h) fourth step. 

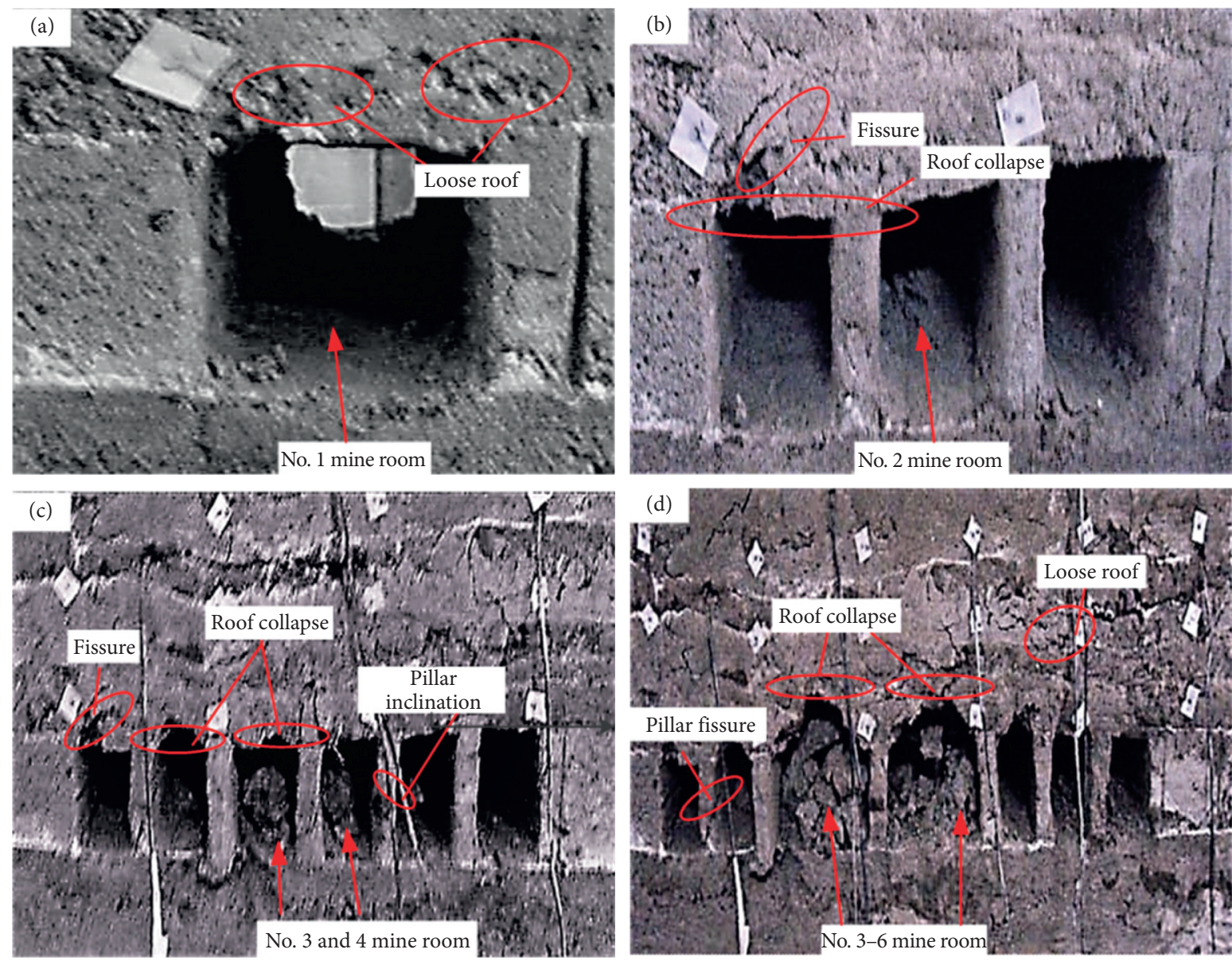

FiguRE 7: Deformation and failure characteristics of the roof for the $3 \mathrm{~m}$ ore pillars: (a) first step; (b) second step; (c) third step; (d) fourth step.

pressure observed at M3 $(3.32 \mathrm{kPa})$. The area of increased pressure moved forward dynamically as the goaf experienced overburden stress. The impact range of the overburden rock subsidence increased from survey line L1 to L2. The maximum subsidence point was at L1-1 and L2-1 at a vertical distance of $15 \mathrm{~m}$ from the roof with a subsidence of $-1.00 \mathrm{~mm}$ (actual size $-29.0 \mathrm{~cm}$ ) and $-0.65 \mathrm{~mm}$ (actual size $-15.6 \mathrm{~cm}$ ), respectively. At the same time, a roof crack with $3.24 \mathrm{~cm}$ and loosening belts appeared in the upper left corner of mine room \#1. Accompanied by a minor collapse, mine rooms \#2 and \#3 were slightly bent.

After the third excavation step, the goaf was expanded into mine room \#6. The roof stress relief area continued to expand, and the stress at each measurement point decreased sharply. The maximum pressure relief position was observed at M5 $(1.42 \mathrm{kPa})$, with $90 \%$ stress reduction. Due to the mining activity, the settlement area of the overlying rock layer expanded horizontally in the direction of the survey line L3 and vertically from $6.2 \mathrm{~cm}$ to $10.4 \mathrm{~cm}$. The maximum subsidence point was at L2-1 with $-2.94 \mathrm{~mm}$ displacement (actual $-70.6 \mathrm{~cm}$ ). It was observed that the points closer to the center of the stope experienced a greater subsidence. Affected by stress and the subsidence of the overlying rocks, the pillars \#1-4 were pushed sideways, and the roof of the stope broke and collapsed.
After the fourth excavation step, the goaf was expanded into mine room \#9, and the stress of the overburden rock in the stope moves forward. The area of maximum pressure relief was observed at $\mathrm{M} 6$, with a stress of $1 \mathrm{kPa}$. The stress of the overlying rock on the stope continually moved forward. The further away from the center of the goaf the survey lines L1, L4, and L5 were, the weaker the effect of the mining on rock mass. The maximum subsidence points were observed at L2-1 and L3-1 with $-14.58 \mathrm{~mm}$ (actual $-350.0 \mathrm{~cm}$ ) and $-13.75 \mathrm{~mm}$ (actual $-330.0 \mathrm{~cm}$ ), respectively. Pillar \#1 had a macrobreak fracture, and the remaining pillars were inclined. The roof of mine rooms \#3-6 in the middle of the goaf experienced a large area of collapse, and the entire physical model was unstable.

\subsection{Stope Deformation and Failure Laws for the Mine Rooms} with $5 \mathrm{~m}$ Ore Pillars. The stress measurement points N1-N6 and the displacement survey lines L18-L22 for the roof of the phosphate ore layer under the stope structure with $2 \mathrm{~cm}$ ore pillars were monitored, as illustrated in Figures 8 and 9. Figure 8 shows the lower roof stress and overlying rock subsidence for the four-step excavation of the stope structure with $5 \mathrm{~m}$ ore pillars. Figures $8(\mathrm{a})$ and $8(\mathrm{~b})$ represent the 


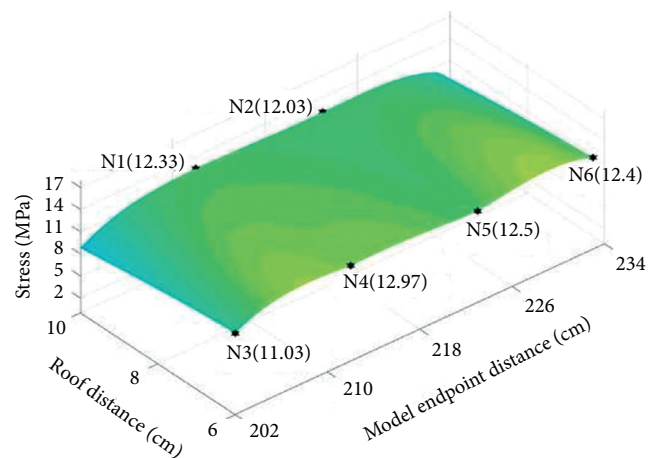

(a)

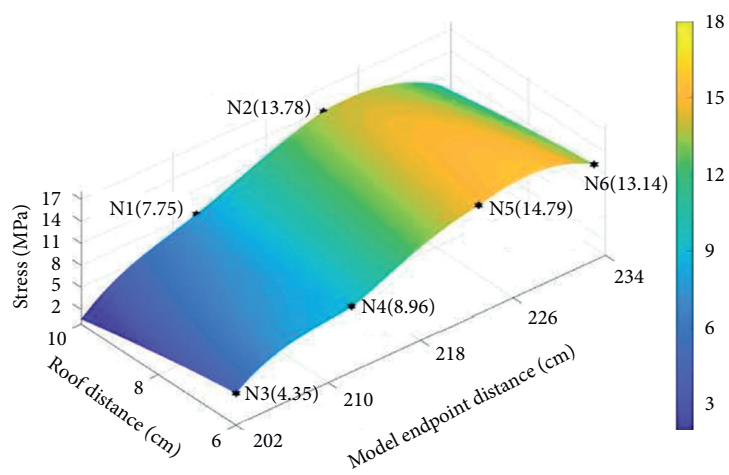

(c)

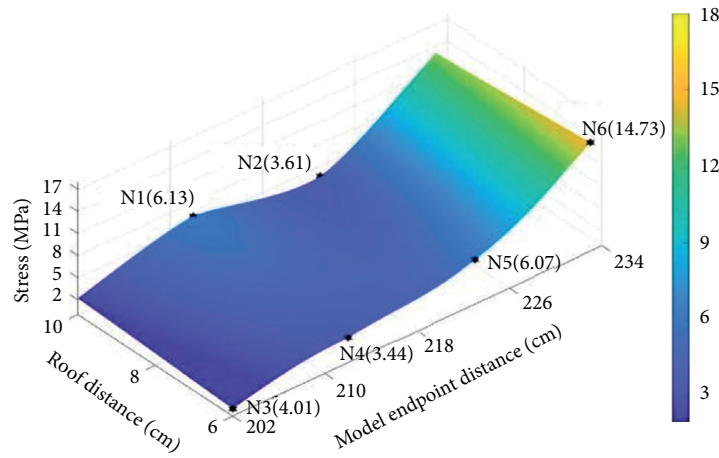

(e)

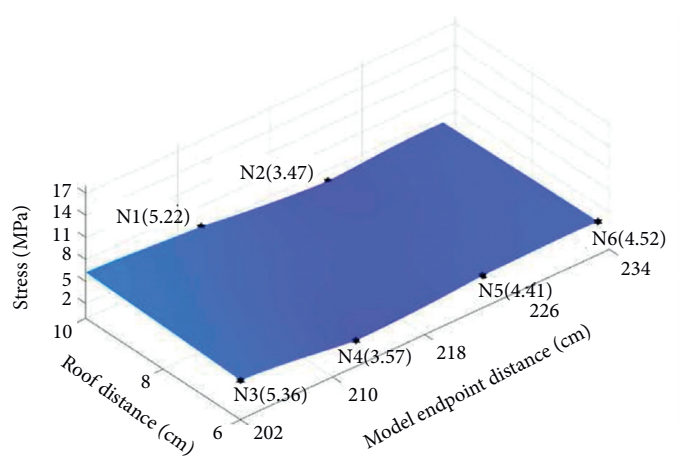

(g)

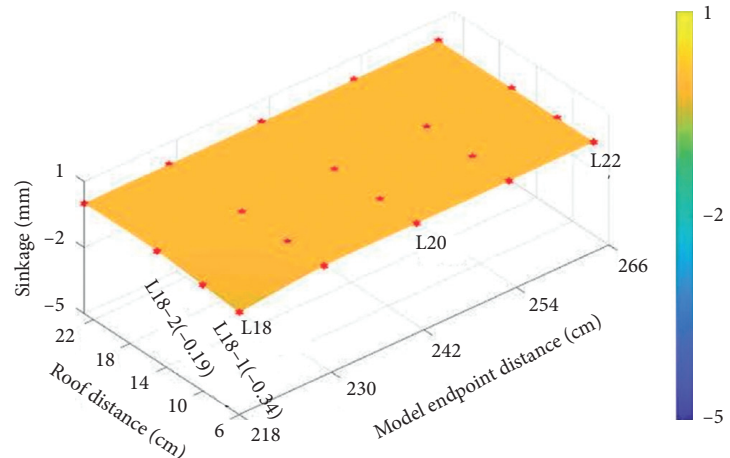

(b)

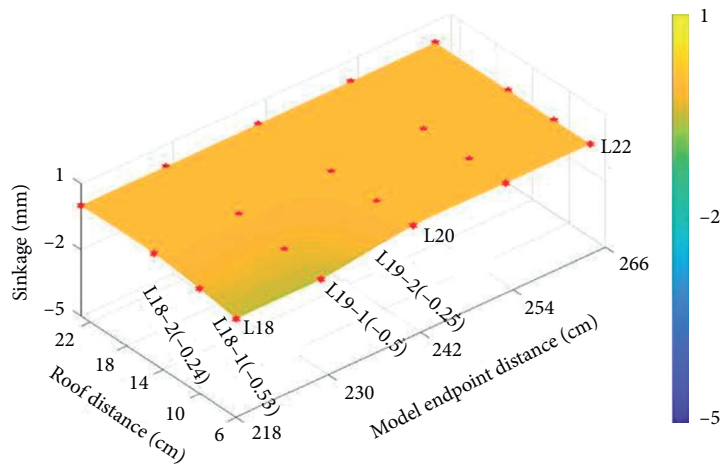

(d)

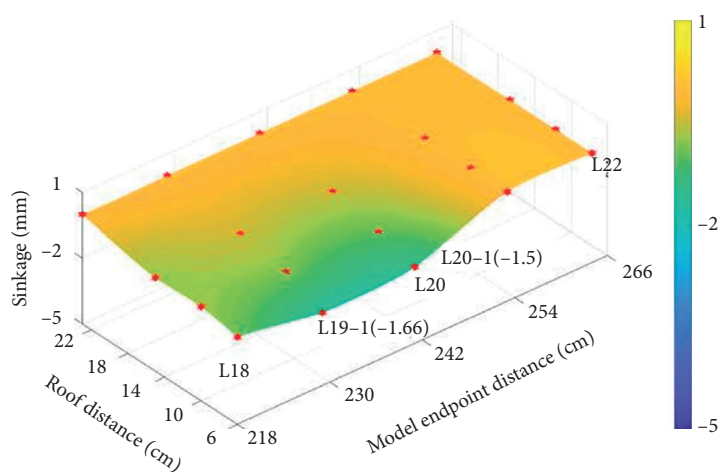

(f)
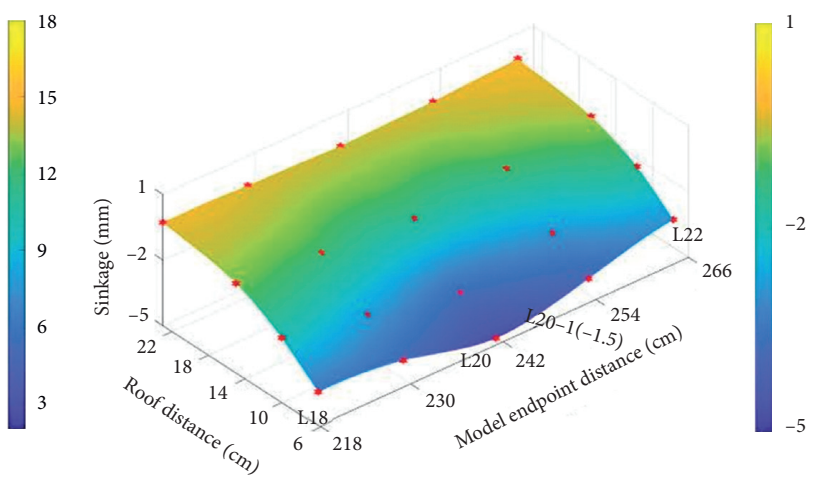

(h)

FIGURE 8: Lower roof stress and overlying rock subsidence in the four-step excavation of the stope structure with $5 \mathrm{~m}$ ore pillars: (a, b) first step; (c, d) second step; (e, f) third step; and (g, h) fourth step. 

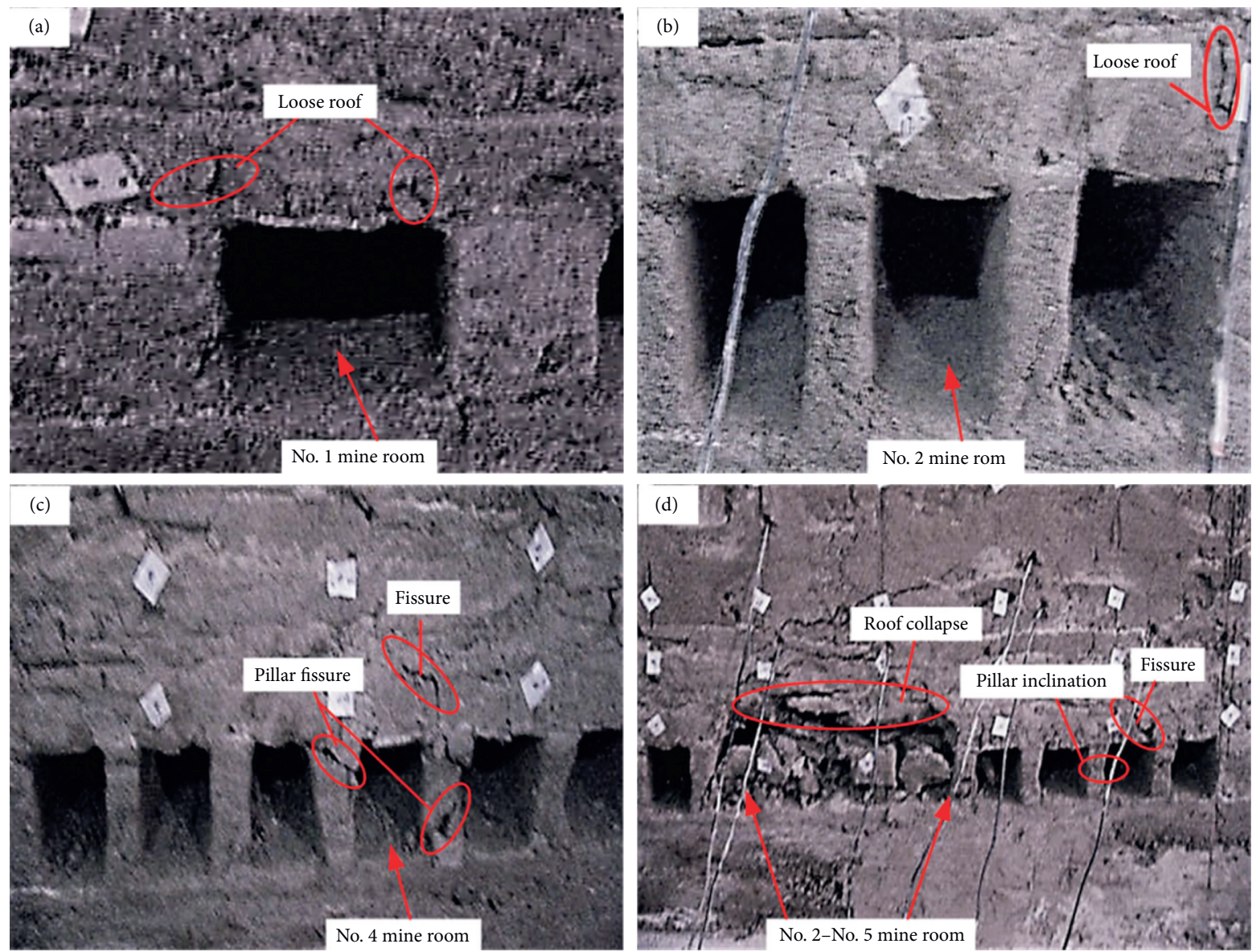

Figure 9: Deformation and failure characteristics of the roof for the $5 \mathrm{~m}$ ore pillars: (a) first step; (b) second step; (c) third step; (d) fourth step.

first step of excavation; Figures 8(c) and 8(d) represent the second step of excavation step; Figures $8(\mathrm{e})$ and $8(\mathrm{f})$ represent the third step of excavation; Figures $8(\mathrm{~g})$ and $8(\mathrm{~h})$ represent the fourth step of excavation. Figure 9 shows the deformation and failure characteristics of the roof for the $5 \mathrm{~m}$ ore pillars. Figure 9 (a) represents the deformation and failure characteristics of the roof of the first step of excavation; Figure 9(b) represents the deformation and failure characteristics of the roof of the second step of excavation; Figure 9(c) represents the deformation and failure characteristics of the roof of the fourth step of excavation. The displacement measurement points were labeled LB-1, LB-2, LB-3, LB-4, and LB-5 according to their vertical distance from the stope roof $(6.25 \mathrm{~cm}, 10.4 \mathrm{~cm}, 14.5 \mathrm{~cm}$, and $22.9 \mathrm{~cm}$, respectively), with $B$ representing the line number.

After the first excavation step, the roof above the stope exhibited a stress relief area. The maximum stress relief was observed at N3, which fell from $12.40 \mathrm{kPa}$ to $11.03 \mathrm{kPa}$. In contrast, the stress at the measurement points N1, N2, N3, $\mathrm{N} 4$, and N5 was $12.33 \mathrm{kPa}, 12.03 \mathrm{kPa}, 12.97 \mathrm{kPa}, 12.50 \mathrm{kPa}$, and $12.40 \mathrm{kPa}$, respectively. The stress at measurement point N6 remained at $12.40 \mathrm{kPa}$. Overall, the increased degree of stress at each measurement point decreased with increasing distance from the goaf. Affected by mining, the subsidence of survey points L18-1 and L18-2 was $-0.34 \mathrm{~mm}$ (actual
$-8.2 \mathrm{~cm}$ ) and $-0.19 \mathrm{~mm}$ (actual $-4.6 \mathrm{~cm}$ ), respectively. Only a small loose band appeared at both corners of the top plate, and the model was generally stable.

In the second step of the excavation, the range of the goaf extended to mine room \#3, and the stress relief area in the stope transferred dynamically to the front rock mass. The stress at measurement points $\mathrm{N} 1, \mathrm{~N} 3$, and $\mathrm{N} 4$ exhibited a gradual decrease with an increase in the distance from the center of the goaf. At measurement point N3 above the goaf, the stress was $4.35 \mathrm{kPa}$ and $60 \%$ lower than the initial value. The measurement points N2, N5, and N6 were in the area of increased stress, with a maximum stress of $14.79 \mathrm{kPa}$ at N5. The maximum subsidence area in the overlying rock layer was observed at survey lines L18 and L19. The subsidence at L18-1 and L18-2 was measured as $-0.53 \mathrm{~mm}$ (actual $-12.6 \mathrm{~cm}$ ) and $-0.24 \mathrm{~mm}$ (actual $-5.9 \mathrm{~cm}$ ), respectively. Besides, the subsidence at L19-1 and L19-2 was obtained at $-0.5 \mathrm{~mm}$ (actual $-11.9 \mathrm{~cm}$ ) and $-0.25 \mathrm{~mm}$ (actual $-6 \mathrm{~cm}$ ), respectively. Mine room \#3 exhibited obvious roof loosening and collapse in response to mining activity.

After the third step of the excavation, the goaf was expanded into mine room \#6. The roof stress relief area again moved to the front rock body. The stress at N4 and N5 at the center of the goaf fell to $3.44 \mathrm{kPa}$ and $6.07 \mathrm{kPa}$, respectively. Measurement point N2 quickly switched from an area of 
increased stress in top plate to a pressure-relieving area, with the stress falling to $3.61 \mathrm{kPa}, 70 \%$ lower than the initial value. The measurement point N6 was located in the zone of increased stress, and a stress of $14.73 \mathrm{kPa}$ was recorded. The subsidence area of the overlying rock expanded from $6.2 \mathrm{~cm}$ to $14.5 \mathrm{~cm}$ along the horizontal direction of the orebody, but the extent of the subsidence at each measurement point decreased in sequence. The maximum subsidence at L19-1 and L19-2 was $-1.66 \mathrm{~mm}$ (actual $-39.90 \mathrm{~cm}$ ) and $-1.50 \mathrm{~mm}$ (actual $-36.00 \mathrm{~cm}$ ), respectively. Macrocracks appeared on the roof of mine rooms \#4 and \#5, and fractures appeared in the ore pillars.

After the fourth excavation step, the goaf was extended to mine room \#9. The stress relief boundary range expanded to the measurement point N6, with the stress falling from $14.73 \mathrm{kPa}$ to $4.52 \mathrm{kPa}$ and $70 \%$ lower than the initial value. In the area behind the old goaf, the measurement point N3 experienced gradual compaction due to the subsidence of the overlying rock layer. The stress at N3 increased from $4.01 \mathrm{kPa}$ to $5.36 \mathrm{kPa}$. The influence of overburden rock subsidence also increased, with the overburden rock subsidence area expanding from $6.2 \mathrm{~cm}$ to $22.9 \mathrm{~cm}$ away from the roof along the horizontal direction of the orebody. The maximum subsidence at $\mathrm{L} 20-1$ was $-4.67 \mathrm{~mm}$ (actual $-112.00 \mathrm{~cm}$ ). A transfixion macrocrack appeared on the roof of mine room $\# 2-5$. The remaining mine pillars leaned, and the \#2-5 mine room collapsed.

6.3. Stope Deformation and Failure Laws for the Mine Rooms with $8 \mathrm{~m}$ Ore Pillars. For the stope structure with $8 \mathrm{~m}$ ore pillars, the results from the stress measurement points P1-P6 and the measurement lines L9-L14 from the roof of the phosphate ore layer are presented in Figures 10 and 11. Figure 10 shows the lower roof stress and overlying rock subsidence for the four-step excavation of the stope structure with $8 \mathrm{~m}$ ore pillars. Figures $10(\mathrm{a})$ and 10(b) represent the first step of excavation; Figures 10(c) and 10(d) represent the second step of excavation step; Figures 10(e) and 10(f) represent the third step of excavation; and Figures $10(\mathrm{~g})$ and 10 (h) represent the fourth step of excavation. Figure 11 shows the deformation and failure characteristics of the roof for the $8 \mathrm{~m}$ ore pillars. Figure 11 (a) represents the deformation and failure characteristics of the roof of the first step of excavation; Figure 11(b) represents the deformation and failure characteristics of the roof of the second step of excavation; Figure 11(c) represents the deformation and failure characteristics of the roof of the fourth step of excavation. The displacement measurement points were labeled LB-1, LB-2, and LB-3 for vertical distances of $6.25 \mathrm{~cm}, 10.4 \mathrm{~cm}$, and $14.5 \mathrm{~cm}$, respectively.

After the first excavation step, mine room \#1 was the goaf. A stress relief area formed around measurement point $\mathrm{P}$ 3, with the stress falling from $12.4 \mathrm{kPa}$ to $12.3 \mathrm{kPa}$. The overpressure zone from the overburden stress in the stope dynamically shifted to the front rock mass, and the maximum stress at $\mathrm{P} 4$ increased to $12.84 \mathrm{kPa}$. The subsidence at L9-1 was $-0.18 \mathrm{~mm}$ (actual $-4.4 \mathrm{~cm}$ ), while the remaining subsidence measurement points did not subside. The structure of the mine room was very stable.
In the second step of the excavation, the goaf area expanded to mine room \#3. The stress relief area of the roof expanded, with the maximum stress at P3 falling from $12.30 \mathrm{kPa}$ to $5.12 \mathrm{kPa}, 63 \%$ lower than the initial value. The overburden stress in the stope formed a pressurization zone. The maximum stress at P5 increased from $12.44 \mathrm{kPa}$ to $14.22 \mathrm{kPa}$ and $14 \%$ lower than the initial value. At the same time, the subsidence range of the overlying rock expanded from the measuring points L9-1 to L10-1, with subsidence of $-0.33 \mathrm{~mm}$ (actual $-7.92 \mathrm{~cm}$ ) and $-0.28 \mathrm{~mm}$ (actual $-6.72 \mathrm{~cm}$ ), respectively. Though the roof plate in mine rooms $\# 1$ and \#2 exhibited obvious bending, the overall structure of the model was stable.

After the third excavation step, the range of the goaf was expanded to mine room \#6. The stress relief zone continually moved forward, and the stress at P5 fell from $14.22 \mathrm{kPa}$ to $4.41 \mathrm{kPa}$ and $68 \%$ lower than the initial value. The stress at P6 in the goaf pressurization area rose from $13.04 \mathrm{kPa}$ to $17.36 \mathrm{kPa}$ (33\% lower than the initial value). Considering measurement points P1 and P4 in the center of the goaf as the axis of symmetry, the stress relief of the roof gradually exhibited a saddle-shaped distribution. The range of overburden rock subsidence expanded further, and the overburden rock subsidence area expanded from $6.2 \mathrm{~cm}$ to $10.4 \mathrm{~cm}$ from the roof along the horizontal direction of the orebody. The maximum subsidence at L10-1 was $-1.44 \mathrm{~mm}$ (actual $-34.6 \mathrm{~cm})$. Bending and subsidence occurred in the roof of each mine room, and a clear crack appeared in the middle of the roof in mine rooms \#3 and \#4, accompanied by minor slippage of loose and broken rock.

After the fourth excavation step, the goaf was expanded to mine room \#9. The stress at each measurement point fell within the stress relief area. The maximum stress at P6 reduced from $17.36 \mathrm{kPa}$ to $3.88 \mathrm{kPa}$ and $77 \%$ lower than the initial value. At this time, mine rooms \#1 and \#2 were located in the old goaf. The stress at measurement point P3 increased from $5.09 \mathrm{kPa}$ to $7.38 \mathrm{kPa}$. That is because the roof gradually compacted after falling, supported by overburden gravity. The range of overburden subsidence extended horizontally to L14 and gradually increased to $14.5 \mathrm{~cm}$ along the horizontal direction of the orebody. The maximum subsidence at L11-1 was $-3.48 \mathrm{~mm}$ (actual $-83.6 \mathrm{~cm}$ ). With an increase in the distance from the center of the goaf, the degree of subsidence decreased monotonously. The bending of the roof in each mine room increased, and some of the pillars were inclined. However, there was no collapse, and the model was basically stable.

\section{Discussion}

7.1. Stress and Displacement Deformation Laws for the Surrounding Rock in the Stope. The changes in the stress and displacement of the surrounding rock in the stope reflect the stability of the overlying strata. In the early stages of phosphate rock mining, the original stress equilibrium of the surrounding rock is disrupted. In the present study, the stress and displacement deformation failure of the surrounding rock for different ore pillar sizes exhibited some general rules as follows. 


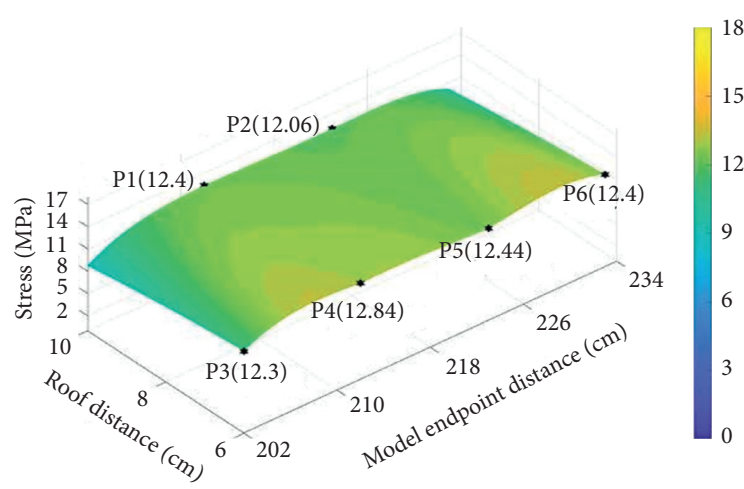

(a)

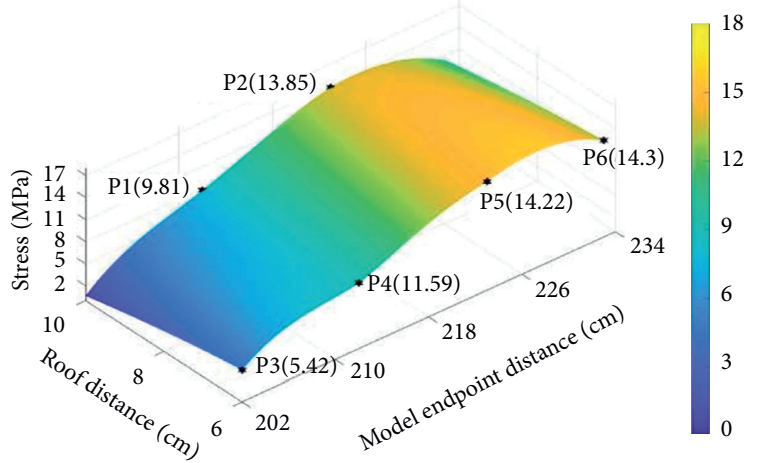

(c)

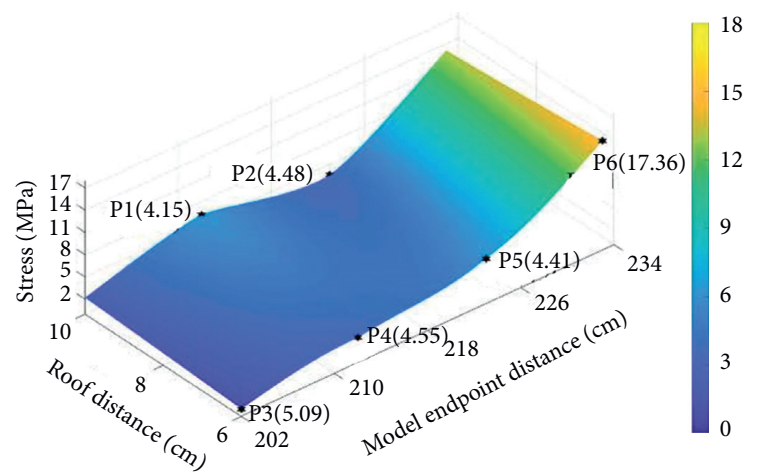

(e)

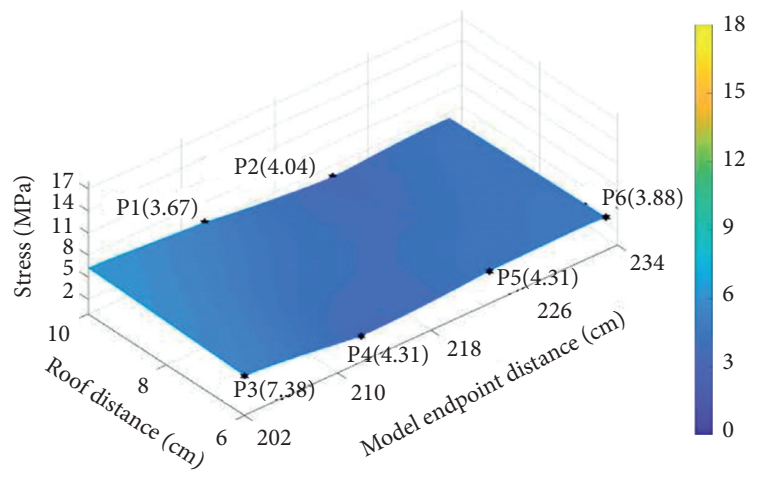

(g)

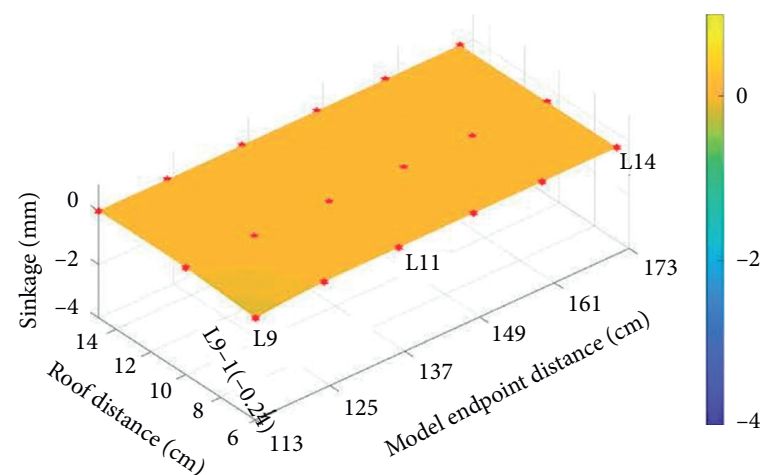

(b)

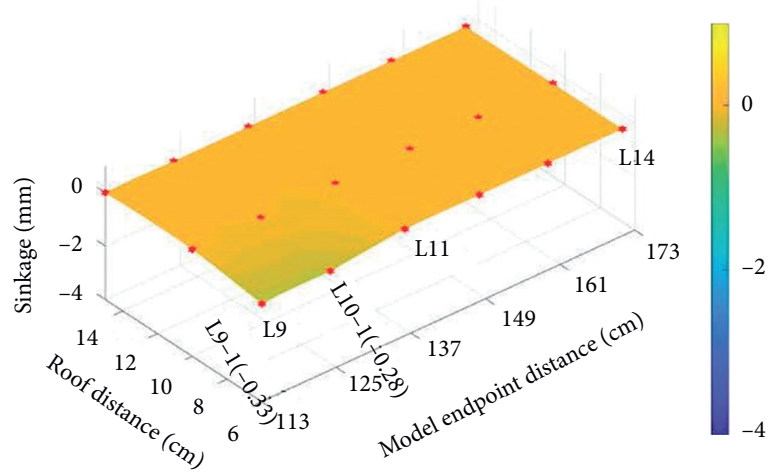

(d)

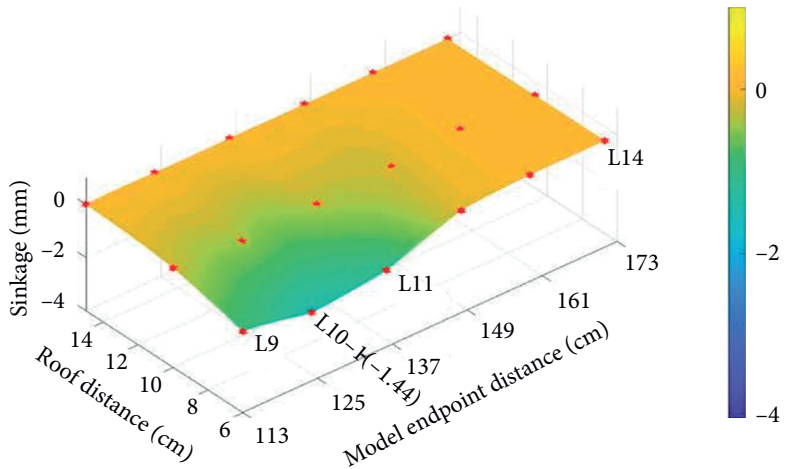

(f)

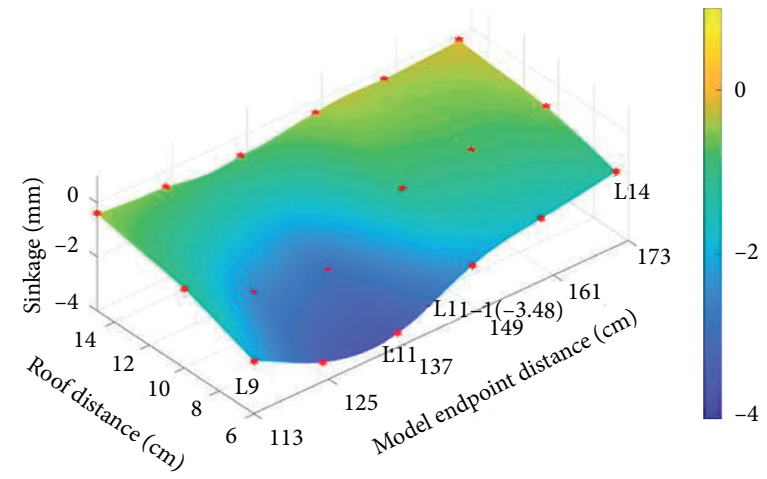

(h)

FIGURE 10: Lower roof stress and overlying rock subsidence in the four-step excavation of the stope structure with $8 \mathrm{~m}$ ore pillars: (a, b) first step; (c, d) second step; (e, f) third step; and (g, h) fourth step. 


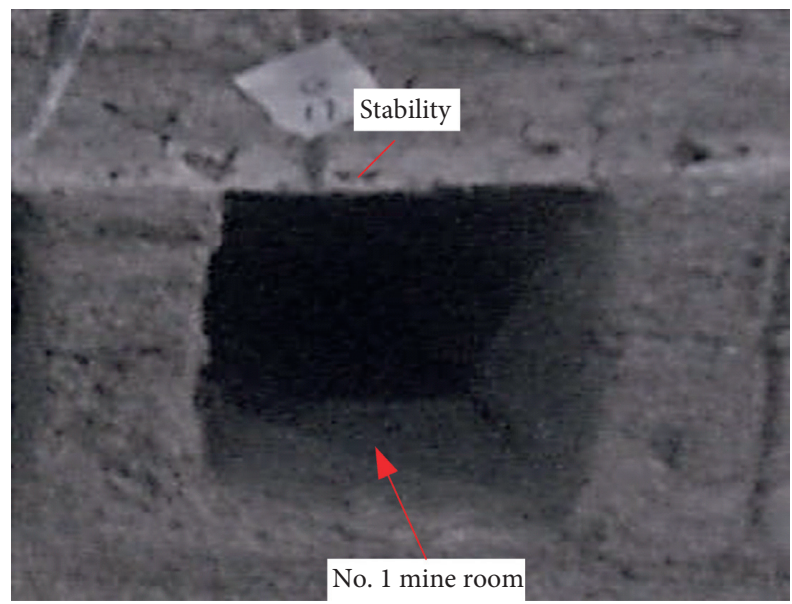

(a)

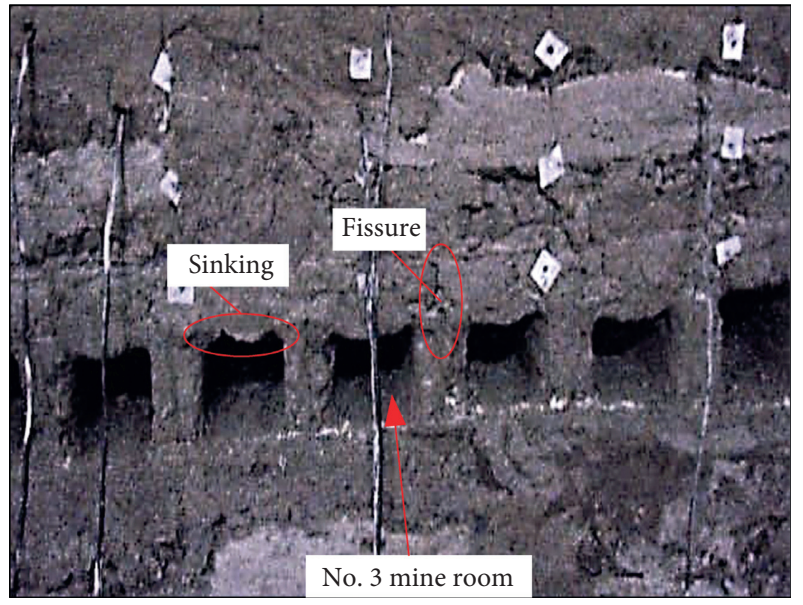

(c)

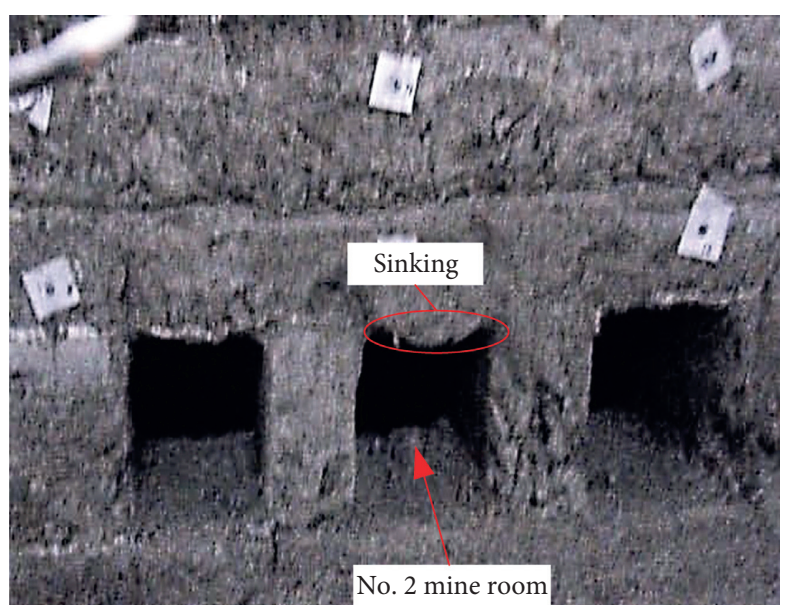

(b)

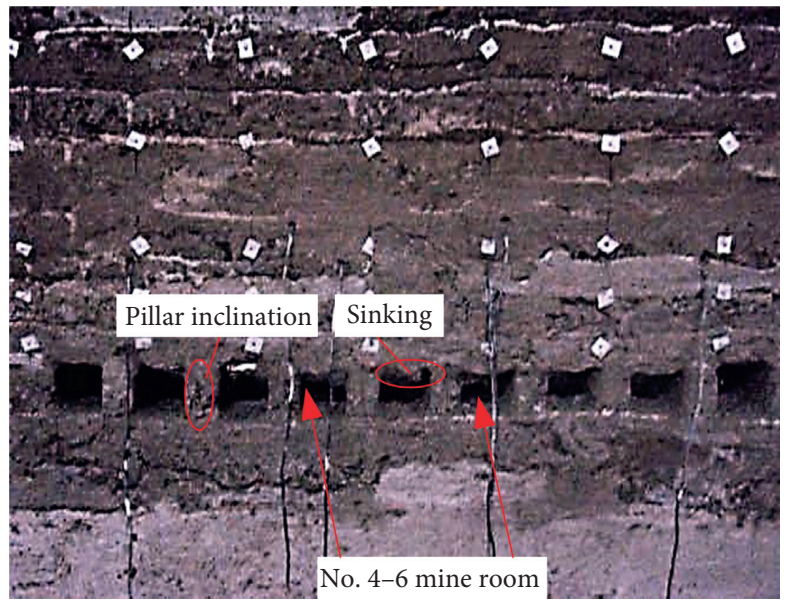

(d)

FiguRE 11: Deformation and failure characteristics of the roof for the $8 \mathrm{~m}$ ore pillars: (a) first step; (b) second step; (c) third step; (d) fourth step.

During the mining process, a pressure relief area first formed in the upper central area of the roof of the goaf. At the same time, the roof began to bend and subside, causing the stress of the overlying rock to move forward within the stope to create a pressurized area. As the working face continued to advance, the stress relief boundary also increased. When the stress of the overlying rock reached its yield state, microcracks began to appear in the overlying rock. In addition, the expansion of the stope space transferred the whole overlying rock layer weight on the pillars $[52,53]$. When the gravity of the overlying rock reached a critical point at the ore pillar, the microcracks gradually generated to form a local fissure zone.

When the excavation of the phosphate orebody was complete, the surrounding rock in the roof of the goaf exhibited obvious deformation and failure characteristics. Three deformation zones could be identified based on the extent of deformation and failure in the overlying rock including bending, fracture, and caving zones, as shown in Figure 12.
The fracture zone had an obvious layered structure, and the inside of the rock mass exhibited both vertical layered fissures and separated layer fissures in the horizontal direction.

The rock mass in a caving zone is affected by mining disturbances, and the distribution is disordered. In addition, the caving zone has a loose internal structure, and it is also compressible. The caving and the fracture zone are collectively referred to as the water-conducting fissure zone. When vertical stress is applied to the upper region of the waterconducting fissure zone, a superimposed compressive effect occurs between the two zones, resulting in uneven settlement.

In the present study, as the excavation advanced, the stress and subsidence of the overlying rock layer increased dramatically. The variation in the subsidence was associated with the spatial distance along the orebody and from the stope. In other words, as the distance along the orebody and from the stope is greater, the influence of each moving line is weaker; the bearing capacity of the surrounding rock is 


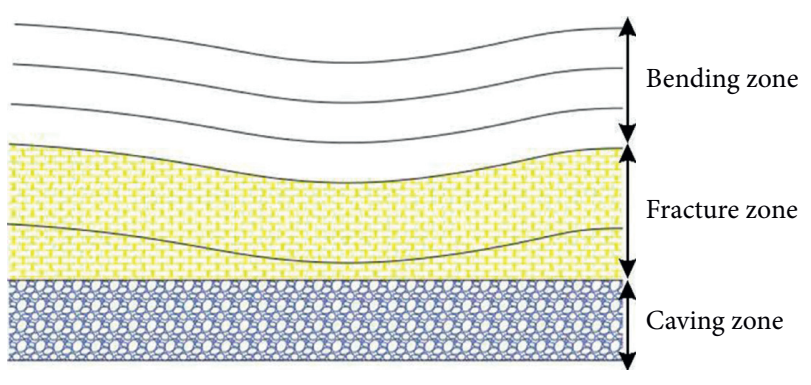

FIGURE 12: Overlying strata movement zones in a goaf.

stronger, the subsidence of the overlying rock is lower, and the deformation of the surrounding rock is less.

7.2. Determining the Optimal Stope Structure. The pillars are crucial to the overall stability of the stope in room and pillar mining. Once a pillar is unstable, the surrounding rock in the roof will fall, increasing the difficulty in mining the orebody and the dilution rate of the orebody. In addition, the sudden collapse of a stope can also cause casualties. The characteristics of stress deformation and failure in the roof and the subsidence of overlying rock depend on the pillar size. Generally, a larger pillar size produces a more stable stope structure. However, larger pillar sizes can lead to the waste of resources and increase mining costs. For this reason, the mining disturbance coefficient and subsidence coefficient $[7,54,55]$ were used in the present study to quantitatively analyze the stope structures with $3 \mathrm{~m}, 5 \mathrm{~m}$, and $8 \mathrm{~m}$ pillars, and finally, it was determined which structure maximized the return on mining activity while also ensuring mine safety.

The mining disturbance coefficient is defined as the ratio of the maximum variation in stress to the initial stress for each excavation in the stope structure. It reflects the degree of disturbance of the mining stress on the surrounding rock in the stope roof, as shown in (1). The subsidence coefficient is the ratio of the maximum subsidence of the overlying strata to the mining thickness of the phosphate rock under the full mining of the stope structure, which reflects the degree of influence the mining disturbance on the overlying rock, as shown in (2):

$$
K_{\max }=\left|\frac{\left(\sigma_{i}-\sigma_{1}\right)_{\max }}{\sigma_{0}}\right| \in[0,+\infty),
$$

where $\sigma_{i}$ is the stress of each excavation step (MPa), $\sigma_{1}$ is the stress of the first excavation step (MPa), and $\sigma_{0}$ is the initial stress $(\mathrm{MPa})$.

$$
W=\frac{W_{\max }}{D},
$$

where $W$ is the maximum subsidence of the overlying rock $(m)$ and $D$ is the thickness of the orebody mined $(m)$. The thickness of the orebody in this study is $5.4 \mathrm{~cm}$.

In Figure 13(a), it indicates that the disturbance coefficients increased for the first three excavation steps in all three kinds of stope structures. When mine rooms \#4-6 were excavated after the third step, an inflection point (the disturbance coefficient began to decrease) appeared in the stope structures with $3 \mathrm{~m}$ and $5 \mathrm{~m}$ pillars. These results are related to the continuous increase in the stope space and the superposition of mining stress as the roof span became larger. Due to the weight of the rock and tectonic stress, the roof bent and subsided, causing cracks to appear in the pillars supporting the overlying strata. Once the ultimate load of the pillars was reached, some of the mine rooms collapsed, and the collapsed broken rock mass was gradually compacted by the weight of the overlying strata, enabling pillars to support the overlying strata. Therefore, the stress disturbance coefficient of the fourth mining step decreased.

Figure 13(b) shows the overlying rock subsidence coefficient for the three stope structures. By comparing the subsidence coefficient for the overlying strata in the three stope structures, it can be concluded that, for the same excavation step, larger pillars produced a lower subsidence coefficient and increased the stability of the overlying strata. In particular, the structural stability of the stope with $3 \mathrm{~m}$ pillars was extremely poor while those with $5 \mathrm{~m}$ and $8 \mathrm{~m}$ pillars were relatively stable.

Overall, the disturbance and subsidence coefficients for the stope structure with $3 \mathrm{~m}$ pillars were larger than those of the other two stope structures. After the third excavation step, the mine rooms \#2-4 collapsed over a wide area, and the entire model was unstable. Following the third step, the stope structure with $5 \mathrm{~m}$ pillars exhibited partial instability in the old stope area. However, if reinforcement is conducted in advance, the stope damage can be prevented. The stope structure with $8 \mathrm{~m}$ pillars was always stable. However, the grade of the phosphate rock in this mining area is $26-30 \%$, and the price of phosphate rock is high. From an economic and safety perspective, a stope structure with $10 \mathrm{~m}$ mine rooms and $5 \mathrm{~m}$ pillars can be used to mine this orebody.

\subsection{Analysis of the Excavation Characteristics and Stope} Structure of Different Ore Types. The shape, metallogenic regularity, stratum structure, and tectonic stress of gently inclined medium-thick phosphate rock are different when compared to metal and coal mines. Thus, there are likely to be differences in the deformation laws for the surrounding rock in the roof and the selection of the optimal stope structure depending on the type of ore being mined. The deformation characteristics of the surrounding rock and the selection of the stope structure are discussed further in this section.

The deformation and failure of the overlying strata in stopes with different orebody characteristics under room and pillar mining have similarities, and differences are summarized in Table 3.

The incline of the orebody affects the characteristics of the overburden deformation. For example, in gently inclined coal seams, there is a tendency for obvious delamination above the excavation area, but no significant delamination is observed in inclined or steeply inclined coal seams. The extent of the deformation is weakened and more uniform, meaning that the damage to the overlying rock layer and the 


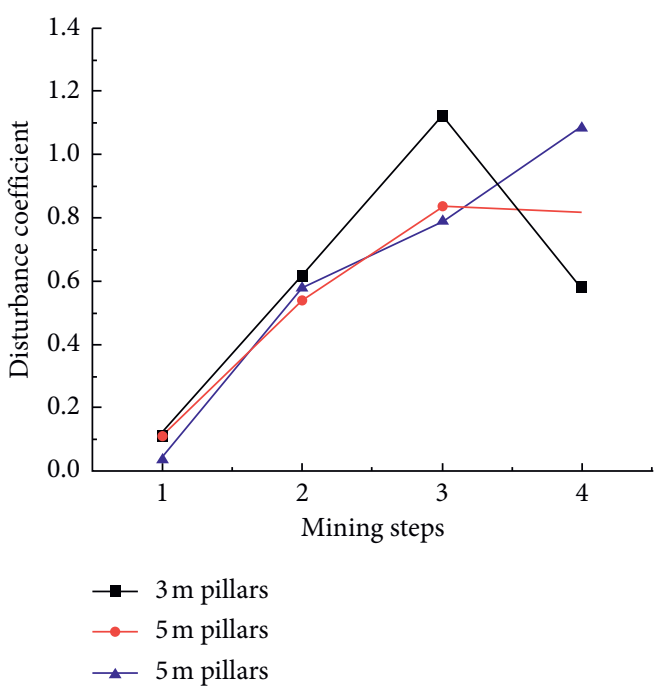

(a)

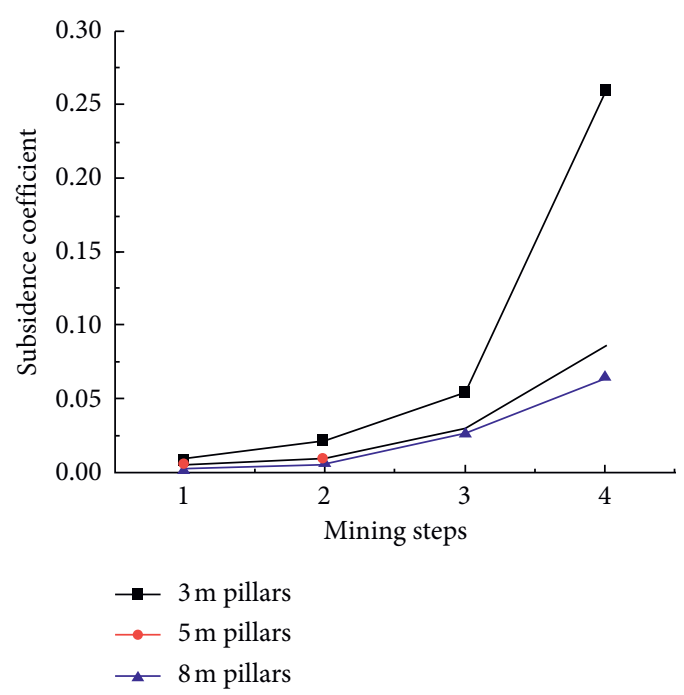

(b)

Figure 13: (a) Mining disturbance coefficient and (b) overlying rock subsidence coefficient for the three stope structures.

TABLE 3: Law of deformation and failure for stopes in various mine types.

\begin{tabular}{|c|c|c|}
\hline Mine characteristics & Differences & Explanation \\
\hline $\begin{array}{l}\text { Gently inclined medium-thick } \\
\text { phosphate rock (the present } \\
\text { study) }\end{array}$ & $\begin{array}{l}\text { The surrounding rock in the roof gradually evolves } \\
\text { from stable to unstable and dynamic balance during } \\
\text { the mining process } \\
\text { In the present study, because of the unique } \\
\text { characteristics of the ore, the overlying rock mass } \\
\text { had obvious bending, fracture, and caving zones }\end{array}$ & $\begin{array}{c}\text { The characteristics and range of the surrounding } \\
\text { rock deformation are closely related to the rock mass } \\
\text { quality, rock layer contact zone, and orebody burial } \\
\text { depth }\end{array}$ \\
\hline $\begin{array}{l}\text { Slowly inclined medium-thick } \\
\text { metal ore [56-59] }\end{array}$ & $\begin{array}{l}\text { In the mining process, the surrounding rock in the } \\
\text { roof exhibits a process of gradual caving, gradual } \\
\text { caving, sudden caving, and then again gradual } \\
\text { caving, sudden caving, and then surface collapses, } \\
\text { which is repeatable and instantaneous }\end{array}$ & - \\
\hline Shallow coal mine [60-63]. & $\begin{array}{l}\text { The coal seam is shallow; thus, the caving zone } \\
\text { caused by deformation and damage to the overlying } \\
\text { rock directly extends to the surface; there are no } \\
\text { subsidence, fracture, or caving zones }\end{array}$ & - \\
\hline
\end{tabular}

For a certain room size, the larger the pillars, the less change in the stress and displacement of the overlying rock and the more stable the stope

During mining, tensile stress forms in the roof of the stope, and the maximum tensile stress appears in the center area of the roof.

degree of roof subsidence are lower. On the deformation of overlying rocks in gently inclined medium-thick phosphate orebodies, obvious delamination also occurs, but whether this deformation in inclined and steeply inclined phosphate orebodies follows similar rules of coal seams in shallow coal mine requires further investigation.

Stope structural parameters are important for assessing stope stability in room and pillar mining. Sherizadeh and Kulatilake [64] investigated nine stope plans for a Guihua copper deposit (thickness of $0.5-0.7 \mathrm{~m}$ ) using the threedimensional numerical simulation of stope stress, safety factors, vertical displacement, and the plastic zone. The results indicated that a mine room span of $10 \mathrm{~m}$ and a pillar size of $3 \mathrm{~m}$ were the optimal structure. However, this stope structure is not suitable for the gently inclined medium- thick phosphate orebody in this study. Although the difference in mechanical properties has a little influence on the stress distribution in different geological conditions, the tensile strength and cohesion of the rock mass are different, and the plastic zone of the surrounding rock in the roof differs from the plastic zone under mining disturbance. Therefore, even with the same stope parameters, there can be significant differences in stope stability [65-68].

\section{Conclusions}

A large-scale similar physical model was conducted to investigate the roof stress, displacement, and overlying rock deformation laws of the No. 6 pit in the Jinning Phosphate Mine. Some valuable conclusions are as follows. 
In the process of underground mining, the roof stress, displacement, and overlying rock deformation laws of gently inclined medium-thick phosphate rock were different from those of other mines (metal mines and coal mines). With the gradual advance in the working face, the stress relief boundary moved forward dynamically, and the value of stress relief, subsidence, and pressurization decreased from the center of the roof to the periphery. With three different stope structures, the $3 \mathrm{~m}$ stope of the pillar took the lead in bending and sinking. The lateral tilt of the pillar caused local cracks, and some mine rooms collapsed. Microcracks appeared in the roof of the $5 \mathrm{~m}$ mine pillar, while the $8 \mathrm{~m}$ pillar structure remains stable during the entire excavation process. Due to the influence of mining, the overlying strata of all three stope structures exhibited bending, fracture, and caving zones.

The best structure for combined mining of gently inclined medium-thick phosphate rock rooms and pillars are the combined mining of $10 \mathrm{~m}$ mine rooms and $5 \mathrm{~m}$ mine pillars and the roof of the mine needs to be reinforced in advance (without considering the action of complex external influence factors (earthquake, rain, and freeze-thaw)).

Through the above research, future research should explore more mining methods for underground mining of sloping medium-thick, gently inclined thin to medium-thick phosphorous deposits, especially the combined mining derived from the existing caving method, open field method, and filling method to further increase the recovery rate of underground mining and reduce the dilution rate.

\section{Data Availability}

The data used to support the findings of this study are included within the article.

\section{Conflicts of Interest}

The authors declare that there are no conflicts of interest regarding the publication of this paper.

\section{Authors' Contributions}

Xiaoshuang Li conceptualized the study and analyzed using software. Zhifang Liu performed formal analysis. Shun Yang wrote the original draft.

\section{Acknowledgments}

This work was supported by the National Natural Science Foundation of China (Grant nos. 41702327 and 41867033), Postdoctoral Science Foundation of China (Grant no. 2019M650144), State Key Laboratory of Safety and Health for Metal Mines (Grant no. zdsys2019-005), and Undergraduate Innovation Project (Grant no. zs-2019-s042). The authors wish to acknowledge these supports.

\section{References}

[1] M. F. Ding, Z. Wang, D. W. Wang, S. H. Wang et al., "The optimization of mining method scheme for gentle dip and filminess ore body," Gold Science and Technology, vol. 22, pp. 56-59, 2014.

[2] K. P. Zhou, J. B. Zhai, P. L. Hu et al., "Study on optimizing stope parameters and false-inclined layout in the gentle dip thin ore-body," Journal of Guangxi University: Natural Sciences Education, vol. 37, pp. 376-381, 2012.

[3] W. Song, W. Xu, J. Du, and H. Wan, "Stability of workface using long-wall mining method in extremely thin and gently inclined iron mine," Safety Science, vol. 50, no. 4, pp. 624-628, 2012.

[4] X. Li, Z. Wang, and J. Zhang, "Stability of roof structure and its control in steeply inclined coal seams," International Journal of Mining Science and Technology, vol. 27, no. 2, pp. 359-364, 2017.

[5] Z.-F. Song, J.-H. Lei, X.-T. Wang, X.-M. Xu, and X.-P. Xin, "Study on roadway parameters of broken compound roof of gently inclined thick coal seam," Energy Procedia, vol. 16, pp. 334-340, 2012.

[6] Q. R. Kang, J. X. Tang, H. Hu, and W.-Z. Zhang, "Stress distribution rule of roadway affected by overhead mining in gently inclined coal seams group," Transactions of Nonferrous Metals Society of China, vol. 21, no. Supplement 3, pp. 529535, 2011.

[7] A. Zingano and A. Weiss, "Subsidence over room and pillar retreat mining in a low coal seam," International Journal of Mining Science and Technology, vol. 29, no. 1, pp. 51-57, 2019.

[8] X. B. Li, D. X. L. Peng, F. Feng, and X. S. Li, "Stability analysis of horizontal insulating pillar in deep mining from caving to filling method on the basis of refined plate theory," Journal of China University of Mining and Technology, vol. 48, no. 3, pp. 484-494, 2019.

[9] J. N. Merwe and M. Mathey, "Probability of failure of South African coal pillars," Journal of the South African Institute of Mining and Metallurgy, vol. 113, no. 11, pp. 849-857, 2011.

[10] D. Hu, P. Wu, K. X. Dong et al., "Study on stope structure parameters and stability for slightly inclined multi-layer ore bodies with room and pillar mining method," China Mining Magazine, vol. 23, pp. 5-8, 2014.

[11] E. Ghasemi and K. Shahriar, "A new coal pillars design method in order to enhance safety of the retreat mining in room and pillar mines," Safety Science, vol. 50, no. 3, pp. 579-585, 2012.

[12] L. Xiu, M. Qiao, and Z. J. Li, "Study on mining method of gently inclined medium thick orebody," Nonferrous Metals: Mine Part, vol. 3, pp. 1-3, 2011.

[13] J. P. Ren, Y. P. Yang, L. Deng et al., "Mining status and development trend of inclined medium thick orebodies at home and abroad," Modern Mining, vol. 40, pp. 1-4, 2013.

[14] Y. Li, K. Li, X. Feng, and M. Cai, "Development and evaluation of artificial expandable pillars for hard rock mining," International Journal of Rock Mechanics and Mining Sciences, vol. 110, pp. 68-75, 2018.

[15] G. B. Yu, P. Yang, and Z. C. Chen, "Study on surrounding rock stability of pillar extraction in thin gently inclined ore body," Journal of China Coal Society, vol. 38, pp. 294-298, 2013.

[16] K. Zhao and Z. G. Li, "Optimization and application of room and pillar mining scheme for gently inclined medium thick orebody," Light Metals, vol. 12, pp. 5-9, 2017.

[17] E. Ghasemi, M. Ataei, K. Shahriar, F. Sereshki, S. E. Jalali, and A. Ramazanzadeh, "Assessment of roof fall risk during retreat mining in room and pillar coal mines," International Journal of Rock Mechanics and Mining Sciences, vol. 54, pp. 80-89, 2012. 
[18] W. B. Guo, Y. F. Zou, and Q. L. Hou, "Fractured zone height of longwall mining and its effects on the overburden aquifers," International Journal of Mining Science and Technology, vol. 22, no. 5, pp. 603-606, 2012.

[19] G. Y. Zhao, L. Zhou, J. Y. Li, and P. Yu, "Reasonable pillar size design and nugget structural parameters optimization in room-and-pillar mining," Journal of Central South University: Science and Technology, vol. 45, no. 11, pp. 3943-3948, 2014.

[20] X. Li and Y. Chai, "Determination of pillar width to improve mining safety in a deep burst-prone coal mine," Safety Science, vol. 113, pp. 244-256, 2019.

[21] X. F. Wang, W. B. Luo, Z. D. Wu et al., "Mechanical evolution law of macroscopic deformation and failure of surrounding rocks in deep mining," Modern Tunnelling Technology, vol. 56, pp. 99-106, 2019.

[22] S. A. Guan, S. Li, Y. Jin, and D. Liu, "Study on overlying strata movement law in backfill mining of gently inclined medium thick orebody," Journal. of Northeastern University. (Natural Science), vol. 40, no. 11, pp. 1630-1635, 2019.

[23] C. Y. Zhang, C. Z. Pu, R. H. Cao, T. T. Jiang, and G. Huang, "The stability and roof-support optimization of roadways passing through unfavorable geological bodies using advanced detection and monitoring methods, among others," Bulletin of Engineering Geology and the Environment, vol. 78, no. 7, pp. 5087-5099, 2019.

[24] C. Y. Zhang, P. Zou, Y. X. Wang, T. T. Jiang, and P. Cao, “An elasto-visco-plastic model based on stress functions for deformation and damage of water saturated rocks during the freezing-thawing process," Construction and Building Materials, vol. 250, 2020.

[25] C. Y. Zhang, Y. X. Wang, and T. T. Jiang, "The propagation mechanism of an oblique straight crack in a rock sample and the effect of osmotic pressure under in-plane biaxial compression," Arabian Journal of Geosciences, vol. 13, no. 15, 2020.

[26] R. H. Cao, R. B. Yao, J. J. Meng, Q. B. Lin, H. Lin, and S. Li, "Failure mechanism of non-persistent jointed rock-like specimens under uniaxial loading: Laboratory testing," International Journal of Rock Mechanics and Mining Sciences, vol. 132, 2020.

[27] R. H. Cao, R. B. Yao, T. Hu, C. S. Wang, K. H. Li, and J. J. Meng, "Failure and mechanical behavior of transversely isotropic rock under compression-shear tests: laboratory testing and numerical simulation," Engineering Fracture Mechanics, vol. 241, 2021.

[28] R. H. Cao, C. S. Wang, R. B. Yao et al., "Effects of cyclic freezethaw treatments on the fracture characteristics of sandstone under different fracture modes: laboratory testing," Theoretical and Applied Fracture Mechanics, vol. 109, 2020.

[29] Y. X. Wang, S. B. Shan, C. Zhang, and P. P. Guo, "Seismic response of tunnel lining structure in a thick expansive soil stratum," Tunnelling and Underground Space Technology, vol. 88, pp. 250-259, 2019.

[30] Y. X. Wang, P. P. Guo, H. Lin et al., "Numerical analysis of fiber-reinforced soils based on the equivalent additional stress concept," International Journal of Geomechanics, vol. 19, no. 11, 2019.

[31] Y. Chen, G. Wen, and J. Hu, "Analysis of deformation characteristics of fully grouted rock bolts under pull-andshear loading," Rock Mechanics and Rock Engineering, vol. 53, no. 3, pp. 2981-2993, 2020.

[32] Y. L. Zhao, L. Y. Zhang, J. Liao, W. J. Wang, Q. Liu, and L. Tang, "Experimental study of fracture toughness and subcritical crack growth of three rocks under different environments," International Journal of Geomechanics, vol. 20, no. 8, 2020.

[33] Y. L. Zhao, L. Y. Zhang, W. J. Wang, Q. Liu, L. M. Tang, and G. Cheng, "Experimental study on shear behavior and a revised shear strength model for infilled rock joints," International Journal of Geomechanics, vol. 20, no. 9, 2020.

[34] Y. L. Zhao, C. S. Zhang, Y. X. Wang, and H. Lin, "Shearrelated roughness classification and strength model of natural rock joint based on fuzzy comprehensive evaluation," International Journal of Rock Mechanics and Mining Sciences, vol. 137, 2021 Available online.

[35] Y. Zhao, C. L. Wang, and J. Bi, "Analysis of fractured rock permeability evolution under unloading conditions by the model of elastoplastic contact between rough surfaces," Rock Mechanics and Rock Engineering, vol. 53, no. 12, pp. 57955808, 2020.

[36] H. Lin, H. Yang, Y. X. Wang, Y. L. Zhao, and R. H. Cao, "Determination of the stress field and crack initiation angle of an open flaw tip under uniaxial compression," Theoretical and Applied Fracture Mechanics, vol. 104, no. 12, 2019.

[37] Y. Chen and H. Lin, "Consistency analysis of Hoek-Brown and equivalent Mohr-coulomb parameters in calculating slope safety factor," Bulletin of Engineering Geology and the Environment, vol. 78, no. 6, pp. 4349-4361, 2019.

[38] S. J. Xie, H. Lin, Y. F. Chen, R. Yong, W. Xiong, and S. Du, "A damage constitutive model for shear behavior of joints based on determination of the yield point," International Journal of Rock Mechanics and Mining Sciences, vol. 128, 2020.

[39] S. Xie, H. Lin, Y. Wang et al., "A statistical damage constitutive model considering whole joint shear deformation," International Journal of Damage Mechanics, vol. 29, no. 6, pp. 988-1008, 2020.

[40] Y. Zheng, C. Chen, F. Meng, H. Zhang, K. Xia, and X. Chen, "Assessing the stability of rock slopes with respect to blockflexure toppling failure using a force-transfer model and genetic algorithm," Rock Mechanics and Rock Engineering, vol. 53, no. 8, pp. 3433-3445, 2020.

[41] Y. Zheng, C. Chen, F. Meng, T. Liu, and K. Xia, "Assessing the stability of rock slopes with respect to flexural toppling failure using a limit equilibrium model and genetic algorithm," Computers and Geotechnics, vol. 124, 2020.

[42] Y. Zheng, C. Chen, T. Liu, H. Zhang, and C. Sun, "Theoretical and numerical study on the block-flexure toppling failure of rock slopes,” Engineering Geology, vol. 263, 2019.

[43] Y. Zheng, C. Chen, T. Liu, D. Song, and F. Meng, "Stability analysis of anti-dip bedding rock slopes locally reinforced by rock bolts," Engineering Geology, vol. 251, pp. 228-240, 2019.

[44] Y. Zheng, C. Chen, T. Liu, H. Zhang, K. Xia, and F. Liu, "Study on the mechanisms of flexural toppling failure in anti-inclined rock slopes using numerical and limit equilibrium models," Engineering Geology, vol. 237, pp. 116-128, 2018.

[45] H. Lin, D. Lei, R. Yong, C. Jiang, and S. Du, "Analytical and numerical analysis for frost heaving stress distribution within rock joints under freezing and thawing cycles," Environmental Earth Sciences, vol. 79, p. 305, 2020.

[46] H. Lin, X. Zhang, R. Cao, and Z. Wen, "Improved nonlinear Burgers shear creep model based on the time-dependent shear strength for rock," Environmental Earth Sciences, vol. 79, p. 149, 2020.

[47] Z. M. He, D. Xiang, Y. X. Liu, Q. F. Gao, and H. B. Bian, "Deformation behavior of coarse-grained soil as an embankment filler under cyclic loading," Advances in Civil Engineering, vol. 2020, Article ID 4629105, , 2020. 
[48] Z.-M. He, Z.-F. Liu, X.-H. Liu, and H.-B. Bian, "Improved method for determining active earth pressure considering arching effect and actual slip surface," Journal of Central South University, vol. 27, no. 7, pp. 2032-2042, 2020.

[49] R. Jiang, F. Dai, Y. Liu, and A. Li, "Fast marching method for microseismic source location in cavern-containing rockmass: performance analysis and engineering application," Engineering, vol. 4, 2021.

[50] X. Fan, X. D. Jiang, Y. X. Liu, H. Lin, K. H. Li, and Z. M. He, "Local stress distribution and evolution surrounding flaw and opening within rock block under uniaxial compression," Theoretical and Applied Fracture Mechanics, vol. 112, 2021.

[51] C. Y. Zhang, Y. X. Wang, H. Ruan, B. Ke, and H. Lin, "The strain characteristics and corresponding model of rock materials under uniaxial cyclic load/unload compression and their deformation and fatigue damage analysis," Archive of Applied Mechanics, pp. 1-6, 2021.

[52] F. F. Liu, B. Q. Liu, C. Zhai, Z. Li, F. Li, and C. Zhou, "Research of real-time effects of horizontal protecting stratum mining based on similar simulation experiment," Procedia Engineering, vol. 26, pp. 431-440, 2011.

[53] Q. Y. Tian, J. T. Zhang, and Y. L. Zhang, "Similar simulation experiment of expressway tunnel in karst area," Construction and Building Materials, vol. 176, pp. 1-13, 2018.

[54] M. Tzalamarias, I. Tzalamarias, A. Benardos, and V. Marinos, "Room and pillar design and construction for underground coal mining in Greece," Geotechnical and Geological Engineering, vol. 37, no. 6, pp. 1729-1742, 2019.

[55] J. J. Song, C. J. Han, P. Li et al., "Quantitative prediction of mining subsidence and its impact on the environment," International Journal of Mining Science and Technology, vol. 22, no. 2, pp. 69-73, 2012.

[56] M. L. Zhong, H. J. Ma, and Y. Lin, "Study on mining methods and stope structure parameters for gently inclined complex orebody," Industrial Minerals \& Processing, vol. 46, pp. 53-56, 2017.

[57] G. H. Yao, A. X. Wu, and Y. M. Wang, "Stability analysis of stope retention pillars in broken rock conditions," Journal of University Science and Technology Beijing, vol. 33, pp. 400405, 2011.

[58] M. S. Kulkova and A. V. Zemtsovskiy, "Optimizing parameters of stopes and pillars for the zhdanov deposit mining," Eurasian Mining, vol. 5, pp. 13-15, 2019.

[59] J. X. Fu, J. H. Du, and Y. Y. Tan, "The falling process and mechanism of concealed gob roof during the caving mining of the gently inclined heavy ore," Journal of Mining Safety Engineering, vol. 34, pp. 891-898, 2017.

[60] B. B. Gao, X. L. Wang, M. L. Zhu et al., "Dynamic development characteristics of "two zones" of overburden in fully mechanized caving face of high gas thick seam with composite roof," Chinese Journal of Rock Mechanics and Engineering, vol. 31, pp. 3444-3452, 2018.

[61] F. Zhang and B. Lehane, "A numerical study to assist assessment of the stability of shallow coal mine goafs," Geotechnical and Geological Engineering, vol. 37, no. 4, pp. 2837-2846, 2019.

[62] F. G. Bell, T. R. Stacey, and D. D. Genske, "Mining subsidence and its effect on the environment: some differing examples," Environmental Geology, vol. 40, no. 1-2, pp. 135-152, 2000.

[63] Y. H. Guo and K. P. Hou, "Stope structural parameters optimization of gently inclined and extremely thin orebody with room and pillar mining method," Electronic Journal of Geotechnical Engineering, vol. 19, pp. 3707-3719, 2014.
[64] T. Sherizadeh and P. H. S. W. Kulatilake, "Assessment of roof stability in a room and pillar coal mine in the U.S. using threedimensional distinct element method," Tunnelling and Underground Space Technology, vol. 59, pp. 24-37, 2016.

[65] X. Liu, Z. X. Liu, A. H. Liu et al., "Chaotic optimization of structural parameters in gold mining field," Journal of Mining and Safety Engineering, vol. 27, pp. 548-552, 2010.

[66] Y. L. Shang, "Similar simulation test research on overburden activity law of "two hard" working face in Sihe No. 2," Coal, vol. 26, pp. 12-14 + 58, 2017.

[67] H. Xiao, Study on Similar Simulation Test of Layered Rock Slope Excavation Process, Kunming University of Science and Technology, Kunming, China, 2014.

[68] J. P. Zheng and Y. J. Feng, "Strata behavior law of fully mechanized top coal caving face based on similar simulation test," Metal Mines, vol. 2, pp. 44-46, 2013. 